(Aus dem anatomischen Institute zu Strassburg.)

\title{
Beiträge zur Kenntniss der Reifungserscheinungen und Befruchtungsvorgänge am Säugethierei.
}

\author{
Von
}

\section{Dr. G. Re in,}

Privat-Docent der Gynäkologie in St. Petersburg.

Hierzu Taf. IX und 6 Holzschnitte.

Eine ausführliche Besprechung der Literaturangaben, besonders was nicht direct das Säugethierei betrifft, liegt nicht im Plane dieser Arbeit. Eine solche Besprechung wïrde kaum gerechtfertigt sein, nachdem gerade in der neuesten Zeit die embryologisehe Literatur mit den ausführlichsten derartigen Zusammenstellungen von der Hand gründlicher Sachkenner, wie O. Hertwig, Hensen, Fol, Balfou r, Balbiani u. A. bereichert worden ist.

Ich werde mich daher auf die Angabe der von mir beobachteten Thatsachen und deren wissenschaftliche Verwerthung beschränken und von der Literatur nur in so weit Notiz nehmen, als sie sich mit meinen Beobachtungen berührt.

Nachdem von Bütschli, Auerbach, Schneider, Fol, Flemming, 0. Hertwig, Selenka, Strasburger, Calberla, van Bambeke, Kupffer, Benecke, Salensky und And. an niederen Thieren (und Pflanzen:Stras burger) neue epochemachende Beobachtungen auf dem Gebiete der Befruchtungslehre gemacht worden sind, tritt das Bedürfniss, die alten classischen Untersuchungen eines Regnerus de Graaff, Cruikshank, Prevost et Dumas, v. Baer, Barry, Bischoff, Reichert, Coste u. A. an Säugethieren wieder aufzunehmen, dringend auf, um so mehr, als seit der Zeit des Erscheinens der oben genannten Arbeiten 
nur wenige Autoren neue derartige Beobachtungen über Säuge: thiere publicirt baben. Erwähnt seien in dieser Beziehung namentlich E. van Beneden's bekannte vorläufige Mittheilung (1876), die bis jetzt aber leider nicht ausfuhrlich publicirt worden ist, dann die Arbeiten von E. van Beneden und Julin ${ }^{1}$ ), ferner die wichtigen Beobachtungen Weil's und Hensen's und endlich Balbiani's, zum Theil gemeinsam mit He n n g u $\mathrm{y}^{2}$ ) angestellte Untersuchungen.

Ich habe diese nicht sehr leichte Aufgabe nur deswegen zu übernehmen gewagt, weil mir die reichen Mittel des Strassburger anatomischen Instituts und die freundliche Unterstiitzung von Professor Waldeyer zur Verfügung standen. Leider ist die Arbeit noch weit davon entfernt, als etwas abgeschlossenes betrachtet werden zu können, doch glaubte ich die Veröffentlichung nicht aufschieben zu sollen, da ich wegen meiner Rückkehr nach St. Petersburg die betreffenden Untersuchungen auf längere Zeit zu unterbrechen gezwungen bin.

\section{Vorbemerkungen, Untersnchungsverfahren, Beobachtung der Brunst und der Copulation.}

Als Untersuchungsobjecte dienten mir hauptsächlich Kaninchen und Meerschweinchen, und zwar fast ausschliesslich während der Brunst und in den ersten 24 Stunden nach der. Copulation. Im ganzen wurden mehr als 50 Thiere verwendet. Die Thiere wurden in Käfigen in meinem Arbeitszimmer gehalten. Wenn man für den Abfluss des Harns aus den Käfigen die nöthige Sorge trägt, genügende Desinfection der Käfige täglich vornimmt und das Strolı in denselben möglichst oft erneuert, so kann man es im Zimmer, vorausgesetzt, dass dieses gut ventilirt ist, bequem aushalten und anch die Thiere bleiben gesund. Am besten scheinen mir eiserne Käfige, welche aus ziemlich dicht stehenden, aber diünnen Stangen gemacht sind, da diese eine genaue und bequeme Beobachtung, so wie eine gute Ventilation und Reinigung ermöglichen. Der

1) Observations sur la maturation, la fécondation et la segmentation de l'oeuf chez les cheiroptères. - Arch. de Biologie I. p. 551.

2) Balbiani: Sur la fécondation chez les vertebrés. - Journ. de Mikrographie $1879-81$. 
Boden muss ausziehbar und aus verzinktem Draht gemacht sein. Ein Kaninchenbock und ein Meerschweinchenbock sind für sehr lange Zeit, für mehrere Dutzende von Weibchen genügend. Die beiden Geschlechter wurden nur während meiner Anwesenheit im Arbeitszimmer zusammengebracht, d. h. mehrere Stunden täglich. Die trächtigen Weibchen brauchen nur in den letzten Tagen der Schwangerschaft von den Männchen isolirt za sein.

Bei einer solchen Beobachtungsart stellt die von einigen Autoren empfohlene Auswahl der schwangeren Weibchen für die Befruchtungsversuche keinen besonderen Vortheil dar. Es ist richtig, dass die Meerschweinchen (Bis ch of f), so wie die Kaninchen (Weil) sich gewöhnlich gleich nach dem Setzen (Werfen) des Weibchens begatten, doch ist diese Regel gewölnlich nur für eine gewisse Jahreszeit - vom Ende März bis Mitte Juli (für Strassburg) guiltig, indessen auch hier nicht ohne Ausnahme. In dieser Jahreszeit aber, welche ohne Frage derartigen Arbeiten die günstigste ist, lassen. auch die nicht trächtigen Weibchen gewöhnlich nur wenige Tage bis zur Copulation vorübergehen. Im ganzen war bei meinen Versuchen die Mittelzahl der Beobachtungstage für die schwangeren wie für die nicht schwangeren Weibchen fast gleich.

Das Vorhandensein der Branst lässt sich nur mit grosser Wahrscheinlichkeit, nicht mit absoluter Genauigkeit bestimmen. Als sicherere Zeichen können für Kaninchen, so wie für Meerschweinchen, folgende angefiihrt werden: Das Thier wird aufgeregter, es läuft und springt im Käfig oft ohne sichtbare Ursache umher, häufig springt es auf die anderen Weibchen und macht Begattungsbewegungen, die Geschlechtstheile sind stark geschwollen und geröthet, die Schleimhaut derselben wird succulent. Bei der Beribrung scheinen die Geschlechtstheile sehr empfindlich zu sein und nimmt dabei das Thier nicht selten eine charakteristische Körperstellung, wie bei der Copulation an. Bei Meerschweinchen, wenigstens im Anfange der Brunst, kann die stark geschwollene Vulva noch, wie gewöhnlich, verklebt sein und kann diese Verklebung erst bei der ersten Copulation durch den Bock zerstört werden. Umgekehrt kann die Vulva auch ausserhalb der Brunstzeit bei schwangeren so wie bei nicht schwangeren MeerschweinchenWeibchen geöffnet, resp. unverklebt sein. Das Kaninchen-Weibchen giebt manchmal während der Brunstzeit bei der Annäherung des Männchens besondere charakteristische Kehllaute von sich. Doch 
öfters fehlt dieses Zeichen ganz und im Gegentheil kommt diese Erscheinung nicht selten bei den schwangeren, oder puerperalen Thieren vor, oder zeigt sich v or dem Eintreten der eigentlichen Brunst. Es scheint aber, dass diese Erscheinung so wie einige der eben erwähnten auf einen gewissen Grad der geschlechtlichen Aufregung hinweist und vielleicht mit der Reifung der Follikel im Ovarium in einem gewissen Zusammenhange steht. Solche Thiere müssen jedenfalls aufmerksamer beobachtet werden.

Die rite vollzogene Copulation erkennt man bekanntlich bei Kaninchen sehr leicht an dem charakteristischen und heftigen Sprunge des Männchens nach hinten am Ende des Actes. Vielleicht kann man diese Erscheinung dadurch erklären, dass die Axen des Penis und der Vagina bei dieser Thierart sich nicht ganz entsprechen, so dass der Bock fur die Ejaculation in die Tiefe der Scheide eine starke Beckenbewegung nach vorn und oben machen muss, so dass der obere Theil seines Körpers sich ganz nach hinten umbiegt. Ohne heftigen Sprung musste er dabei wegen des drohenden Verlustes des Gleichgewichtes niederfallen. Bei einer anderen Race von Kaninchen, wie schon Weil (Wien) erwähnt und ich selbst in Petersburg gesehen habe, fällt der Bock nach der eben erwähnten Beckenbewegung auf die Seite nieder und dabei zieht er auch das fest mit den Vorderpfoten gehaltene Weibchen mit sich fort. Beide liegen dann einen Moment ruhig am Boden.

Die Beobachtung der Copulation bei Kaninchen wird ausserdem bekanntlich dadurch sehr erleichtert, dass nach der ersten Copulation immer noch mehrere in kurzen Zwischenräumen folgen, bis zu Ablauf von 1/4 Stunden.

Gleich nach der Copulation kann man sehr leicht die Spermatozoen, mit kleinen rundlichen Zellen des Samenblasensecretes vermischt, im unteren Drittheil der Vagina nachweisen, doch ist diese Controluntersuchung, wenn man die in beschriebener Weise vor sich gegangene Copulation beobachtet hat, unnöthig.

Etwas schwerer ist der Begattungsact bei Meerschweinchen zu beobachten, so dass einige Autoren es vorziehen, das Alter der Eier nicht von der Copulation selbst an, sondern von der vorhergehenden Geburt an (Hensen) zu rechnen. In solcher Weise verliert man aber eine gewisse Anzahl von Thieren, da die Copulation nicht nach jedem Wurf eintritt, und wenn sie eintritt, manchmal 
nicht unmittelbar, sondern erst nach mehreren Stunden erfolgt. Wenn das Weibchen sich in der höchsten Brunst befindet, so findet die Copulation meist sogleich nach Zulassung des Bockes statt (der Bock scheint immer copulationsfähig zu sein, sofern er nur gesund ist). Das Weibchen nimmt eine charakteristische Körperstellung - mit gestrecktem Rumpfe und gehobenen Becken - ein; ohne activen Antheil des Weibchens scheint auch bei Meerschweinchen wie bei Kaninchen die Immissio so gut wie unmöglich sein. Am Ende der kurzdauernden Begattung macht auch hier das Männchen eine ähnliche Bewegung mit seinem Becken wie beim Kaninchen, um möglichst tief in die Vagina einzudringen. Doch ist hier diese Bewegung nicht so stark und rasch, so dass kein Sprung nach hinten stattfindet. Sogleich nach stattgehabter Copulation belecken beide Thiere ihre Genitalien und nach einigen Momenten wiederholen sie die Begattung 3-4 Mal, aber in sehr kurzer Zeit, d. h. in höchstens $1 / 4$ bis $1 / 2$ Stunde.

Durch mikroskopische Untersuchung des Inhalts der Scheide (Reichert) bin ich niemals zu ganz sicheren Resultaten iiber die stattgehabte Copulation gekommen, da in Folge der enormen Entwickelung des Penis bei Meerschweinchen die meisten Spermatozoen bei der Begattung direct in den Uterus injicirt werden und nur sehr wenige in der Vagina, hauptsächlich in den obersten Theilen derselben bleiben, von wo sie nur schwer und unter grossen Schmerzen des Thieres zu erlangen sind ${ }^{\mathfrak{1}}$ ).

Dagegen kann man manchmal durch einfaches Ansehen der Genitalien des Weibchens einige Minuten bis $1 / 2$ Stunde und mehr nach der Copulation sich Sicherheit darüber verschaffen ob ein Coitus stattgefunden hat oder nicht. Namentlich findet man hier

1) Die eigenthümliche Form des Glans, die im Erectionszustande sich als ein hohler Kegel, genau der Fortio vagin. des Weibchens entsprechend, darstellt, ist auch ohne $Z$ weifel dazu geeignet, um die Injection des Samens direct in die Uterushöhle zu vermitteln. Im Gegentheil ist bei Kaninchen die Vagina ungemein lang - $10 \mathrm{~cm}$ und noch mehr, also wenigstens $4-5 \mathrm{mal}$ so lang als der Penis im Erectionszustande. Daher halte ich es hier für unmöglich, dass die Einspritzung der Samenflüssigkeit direct in den Uterus hinein stattfinde. Es ist bei allen Untersuchungen über Befruchtung sehr wohl auf diese frappanten Unterschiede im anatomischen Baue der Genitalorgane bei den verschiedenen Thieren zu achten. 
nicht selten Partikelchen des geronnenen Secretes der Samenblasen des Männchens, - Massen vom Aussehen gekochter Stärke. Kleine Partikelchen derselben Substanz finden sich manchmal auch im Praeputialsacke des Männchens gleich nach der Ejaculation. Diese Klümpchen sind nichts anderes als Theile des bekannten Pfropfes, der nach Leuck art bei Meerschweinchen die Vagina gleich nach der Ejaculatio seminis vollständig verstopfen sollte. Die Erscheinung wurde später von $\mathrm{B}$ is ch of f und $\mathrm{H}$ e n se $\mathrm{n}$ bestätigt, dagegen von $\mathrm{Re}$ ich er t bestritten. Ich habe mehrere Male dieses interessante Gebilde beobachtet, und zwar stellte es meistentheils einen ganz trenen $\mathrm{Ab}$ druck der Vagina dar. In einem Falle, wo der Pfropf von einem jungen Thiere, das noch niemals geboren zu haben schien, 7 Stunde nach der Copulation, abstammte, hatte derselhe noch einen dünnen Fortsatz nach oben ganz der Höhle des gemeinsamen Uterushalses entsprechend. Dieser Fortsatz theilte sich ferner etwas weiter oben noch in zwei dünne Fädchen, welche den untersten Theilen der beiden Hörner angehörten. Die Fädchen aber waren nicht vollkommen hart, bei dem Herausnehmen des Pfropfes aus der Leiche wurden sie daher abgerissen, während die übrigen Theile des Gebildes zu einem sehr demonstrativen Alcoholpräparate verwendet werden konnten. In anderen Fällen dagegen fand ich, dass der Pfropf nur die obere Hälfte der Vagina ansfüllte oder es war endlich nur eine verschiedene Menge einer halbflüssigen Masse (Reichert) vorhanden. Ob in den letzten Fällen der Pfropf schon ausgestossen worden war (C. Hensen), oder ob die Bildung des Pfropfes keine ganz constante Erscheinung ist, sondern nur vorkommt, wenn der Bock eine längere Zeit vorher keinen Coitus ausgeführt hat, oder ob das von anderen Momenten abhängt, konnte ich nicht sicher entscheiden. Neuerdings haben Lataste (Zool. Anzeiger $1882 \mathrm{Nr} .110$ u. 111) und Hér on Boye r (Ibid. 1881 Nr. 98 und 1882 Nr. 119 und 120) einige interessante Beobachtungen iiber dasselbe Gebilde auch bei den anderen Glires eingestellt. Es geht aus diesen Untersuchungen unter Anderem hervor, dass auch das Weibchen einen wesentlichen Antheil an der Bildung des Pfropfes hat und dass der Pfropf immer später ausgestossen wird.

Einen unfruchtbaren Coitus habe ich niemals, weder bei Kaninchen noch bei Meerschweinchen beobachtet, so dass bei allen meinen Thieren die Copulation mit der Ovulation zusammenfiel (gegen Hensen). 
Im Eintreten der Brunst habe ich keine Periodicität bei den Versuchsthieren bemerkt.

\section{Aufsuchen und Beobachtnng der Eier. - Fixations- und Färbungsmethoden.}

Um eine möglichst grosse Zahl von Eiern im ganz frischen Zustande zu erhalten, tödtete ich die Thiere gewöhnlich nicht vor der Untersuchung, sondern vivesecirte sie in der Narcose. Fïr Kanincben scheinen mir subcutane Aetherinjectionen (3-4 Pravazschen Spritzen für ein mässig grosses Thier) oder Chloral innerlich gegeben, für die Meerschweinchen Chloroforminhalationen (im Anfange der Narcose unter der Glasglocke, später vorsichtig mittels eines in Chloroform getauchten Schwämmchens) die besten Betäu bungsmittel zu sein. In tiefer Narcose wurde der Banchschnitt gemacht und ein Ovarium mit oder ohne Tube rasch herausgeschnitten. Es ist nothwendig die Blutgefässe vorher abzubinden und zwar hat man im letzteren Falle nur eine Ligatur fuir die Vasa spermatica, in ersteren ausserdem noch eine für die Spitze des Uterushorns nöthig. Das breite Mutterband muss dabei auf $1 \mathrm{~cm}$ Breite mitgenommen werden. Dann schliesst man die Bauchwunde mittelst Klemmen oder einer schon vor dem Ausschneiden der Tube angelegten provisorischen Naht und lässt nun das mit einem Tuche bedeckte Thier ruhig in der Narcose liegen, bis die ausgeschnittenen Organe untersucht worden sind. Wenn dann noch das andere Ovarium untersucht werden soll, wird das Thier vorher getödtet.

Das Ovarialei nimmt man aus dem Follikel sehr bequem mittelst eines zugespitzten doppelt geschliffenen Messers, während man auf das Ovarium einen leichten Druck ausiubt. Von der Spitze des Messers streicht man das Ei mit einem Tröpfehen des Liquor Folliculi mittelst einer feinen Nadel auf das Objectglas ab.

Wenn man am Ovarium feine Oeffnungen an den zusammengefallenen Follikeln bemerkt, durch die die Eier schon ausgetreten sind, so präparirt man die Tube von ibrem Mesenterium rasch, aber sehr sorgfältig mit feiner Pincette und Schere ab. Diese Operation ist ziemlich delicat, besonders beim Meerschweinchen, wo die Windungen der sehr feinen und langen Tube sehr dicht liegen. 
Wenn die vorherige Beobachtung der Copulation, wie bei meinen Versuchen, ganz genau war, kann man einen beträchtlichen Zeitverlust vermeiden, indem man nur eine Abtheilung der Tube abpräparirt, in dem man die Anwesenheit der Eier vermuthen kann; z. B. für die Beobachtung einer der interessantesten Erscheinungen nach der Imprägnation, d. h. der Bildung des Spermakernes und Eikernes und ihrer Conjugation, was gewöhnlich 13-17 Stunden nach der Copulation bei Kaninchen zu Stande kommt, braucht man nur das mittlere Drittheil der Tube zu nehmen. Beide übrigen abgeschnittenen Theile bewabrt man am besten zwischen zwei Uhrgläschen in einer feuchten Kammer, die man in einen Brutapparat stellt, auf. In dieser Weise gehen auch in dem Falle die frischen Eier nicht verloren, wenn nan dieselben etwa nicht in dem genannten Theile der Tube anträfe. Die auf einem Objectglase gerade hingelegte Tube wird Behufs Herausnahme der Eier mit einer feinen Schere aufgeschnitten. Nur einmal konnte ich ein Meerschweinchenei in einer nicht aufgeschnittenen Tube bei Syst. IV. Hartnack seben (Weil, Hensen). In der aufgeschnittenen Tube kann man das Kaninchenei auch mit blossem Auge erkennen, was mir aber bis jetzt nur im ersten Drittel der Tube, wo das Ei noch mit der Corona bekleidet ist, und in dem letzten Drittel, wo es schon eine Eiweisschicht besitzt, gelungen ist. In der Mitte der Tube dagegen konnte ich nur mit Hülfe des Mikroscopes das Ei in Situ beobachten. Es ist in diesem Falle, so wie für das Aufsuchen des Meerschweincheneies in der ganzen nicht aufgeschnittenen Tube, eine schwache Vergrösserung (Syst. I Hartn.) mit kleinem Diaphragma zu empfehlen.

Die Untersuchung der Eier in Situ lässt sich meistens nicht genïgend genau vollziehen. Für die rasche und genaue Untersuchung ziehe ich es vor, mich nicht mit dem Auffinden des Eies in Situ abzumühen, sondern ich schabe direct die Schleimhaut der gut entfalteten Tube mit einer langsamen, gleichmässigen Bewegung eines nicht sehr scharfen Messers ab. In dem dabei erbaltenen grossen Tropfen von Schleim mit Epithelien finden sich gewöhnlich alle im betreffenden Theile der Tube gelegene Eier meistens völlig unversehrt. Bei Meerschweinchen ist das Aufschneiden der Tube (Reichert) fast unmöglich, wegen der ausserordentlichen Dünnheit des Organs, besonders wenn es sich um eine rasche Untersuchung: handelt. Ein vorsichtiges Auspressen der Tube (Bisehoff) mit 
einem halb stumpfen Instrumente ist vollkommen gentigend, um ganz unbeschädigte frische Eier in einem mitausgepressten Tropfen von Tubarschleim rasch $\mathrm{zu}$ bekommen.

Bei der angegebenen Technik kann man, bei einiger Uebung, die Tubareier schon 5-7 Minuten nach dem Bauchschnitte unter dem Mikroskope haben.

Die erste Beobachtung macht man am besten ohne Deckgläschen und ohne Zusatzflüssigkeit unter Anwendung schwacher Systeme (bis V. Hartnack). Diese Beobachtung darf wegen des Eintrocknens nur sehr kurze Zeit dauern. Für eine längere und genauere Beobachtung des lebendigen Eies bedeckt man das zu untersuchende Tröpfchen mit einem kleinen (10 $\square \mathrm{mm}$ ) Deckgläschen, nachdem ein Paar kleine Stückchen feines Papier oder ein Paar Härchen untergelegt sind. Dann werden die Ränder des Deckgläschen mit Oel umsäumt und das Präparat auf einen heizbaren Objecttisch übertragen. Ein Zusats einer kleinen Quantität 0,6\% Kochsalzlösung, oder von Blut, an der Peripherie des Tröpfchens, wenn derselbe za klein ist, um den ganzen Raum unter dem Deckgläschen auszuftullen, schadet der Beobachtung gewöhnlich nichts. Auerbach's Compressionsmethode kann nur bei äusserst geringen Compressionsgraden für Kaninchen- und Meerschweincheneier angewendet werden. Bei etwas stärkerem Drucke platzt die Zona sehr leicht an einer oder mehreren Stellen unter Bildung der Micropyle ähnlichen Bilder, und fliesst dabei sehr leicht der Dotter aus.

Die verschiedenen Glaszellen und besonders die feuchte Kammer von Ranvier mit Luftreservoir können mit grossem Nutzen bei derartigen Beobachtungen verwendet werden. Ferner eine im Brutapparate vorräthig gehaltene erwärmte grössere feuchte Kammer, um während der Untersuchung der erst entnommenen Eier den Rest des Ovariums oder der Tube aufzubewahren.

Bei den verschiedenen Vorsichtsmassregeln konnte ich manchmal das lebendige Ei mit amöboiden Bewegungen der Kerne bis 2 Stunden lang beobachten. Gewöhnlich dauerte die Beobachtung des sicher lebendigen Objectes 10-30 Minuten.

Für die Fixirung der Eier babe ich die besten Resultate mit Osmiumsäure $\left(0,1^{0}-1,0 \%\right)$ und nachträglicher 2-3tägiger Einwirkung von Müller'schen Flüssigkeit und Einschliessung in Glycerin nach Ed. van Beneden gesehen. Man bekommt nach dieser 
Methode wirklich prachtvolle Präparate, welche den Bildern von lebendigen Eiern sehr wenig nachstehen. Nach geniigendem Waschen mit destillirtem Wasser können solche Präparate auch gefärbt werden. Die besten Färbemittel sind Alauncarmin nach Gre$\mathrm{n}$ acher und von Anilinfarben Safranin. Chrom-, Essig- und Salpetersäure, letztere auch in der von Flemming neuerdings empfohlenen starken Concentration, so wie Essigcarmin nach Schneider haben mil bis jetzt keine guten Resultate ergeben.

\section{IIl. Die Reifungserscheinungen.}

Die sogenannte.Corona radiata bestebt bekanntlich aus spindelförmig umgewandelten Zellen des Discus proligerus. B i sc ho ff hält diese Erscheinung für das am meisten characteristische Zeichen der Reife des Eies. Meine eigenen Beobachtungen stimmen damit theilweise überein. Ich fand mehrere Male, dass die Corona radiata besonders klar und characteristisch an denjenigen Eiern erschien, die von brünstigen Thieren, einige Stunden nach der Copulation entnommen waren. Am schärfsten ausgeprägt habe ich sie 9-11 Stunden nach der Copulation bei Kaninchen gesehen, d. b. unmittelbar vor dem Platzen des Follikels, wo auch meist schon ein Richtungskörperchen autsgetreten war und wo ein Theil der Follikel in demselben Ovarium schon geplatzt war. Auch beim Schwein habe ich dasselbe gefunden. - In solchen Fällen sieht man, dass auch andere, entfernter vom Ei gelegene Elemente des Discus proligerus einer besonderen characteristischen Formumwandlung unterliegen. Die Zellen (Fig. 1) sind bedeutend in die Länge gezogen, von Spindel und Sternform mit langgestreckten, oft mehrfach verzweigten Fortsätzen, mittelst derer sie untereinander vielfach anastomosiren. Es ist dieser Befund auch in allgemein anatomischer Beziehung von Interesse, insofern als Epithelzellen von dieser Form und mit derartigen Anastomosen bei den Säugethieren sehr selten sind - meines Wissens sind sie bis jetzt nur aus der Schmelzpulpa der Zahnanlage bekannt (Kölliker). Die so umgewandelten Zellen bilden lange mit einander gekreuzte Züge in der Form eines Balkennetzes. Das ganze Bild erinnert an die Retinacula Barry's, die auch von Coste und neuerdings von $\mathrm{Hensen}$ besehrieben sind.

Es ist nun sehr bemerkenswerth, dass die so umgeformten, 
auf' der Zona pellucida sitzenden Flemente sehr leicht ihre frithere Form wieder annehmen können. So besteht, wie bekannt, die Corona radiata der Eier, welche im Anfange der Tube angetroffen werden, wieder aus meistens cubischen etwas rundlichen Zellen (ef. Fig. 8). Dieselbe Erscheinung habe ich manchmal nach der Einwirkung einiger nicht momentan fixirenden Reagentien beobachtet.

Diese leichte Umwandlungsfähigkeit in die ursprüngliche Form war wahrseheinlich eine der Ursachen, derentwegen Reic hert dieses Zeichen der Maturität, d. h. die Corona radiata, bestritten hat und nur als eine optische Täuschung betrachtete. Ausserdem ist es möglich, dass er nicht vollkommen reife Eier vor sich hatte. Meiner Ansicht nach können Eier aus einer Zeit, die auch nur einige Stunden vor dem Platzen des Follikels liegt, noch nicht als vollkommen reif betrachtet werden. - Als eine der Ursachen der Umwandlung der Follikelepithelzellen in die Spindelform kann wahrscheinlich die Ausdehnung des Follikels durch den angesammelten Liquor Folliculi betrachtet werden, ein Vorgang, der besonders stark in den letzten Stunden vor dem Platzen des Follikels statt hat. Nach dem Platzen des Follikels nehmen die Zellen des Discus wieder (sei es in Folge ihrer Elasticität oder auch einer activen Bewegungsfähigkeit (?) die ursprüngliche Form an. Dies kommt aber nicht sogleich nach dem Austritte des Eies zu Stande. Wenigstens habe ich einmal eine volle schöne Corona am Tubarei gesehen, das höchstens vor einer Stunde, während des Experimentes selbst, ausgetreten war und sich (distal) an der Grenze des ersten und zweiten Drittels der Tube befand (s. unten Beobachtung 5).

Dieselbe Beobachtung wirft ein Licht auf die physiologische Rolle der Corona. Die Vorwärtsbewegung des Eies in der Tube ist kaum durch die Wirkung des Flimmerepithels allein verständlich, jedenfalls kommen antiperistaltische Bewegungen der Tube auch dabei in Betracht, da das Ei, wenn es der vollen Wirkung der Flimmerung allein unterworfen wäre, viel rascher das Tubenrohr passiren müsste, als es das thut. Soll aber die Eigenbewegung der Tube auf das Ei wirken können, so muss dieses durch eine festanbaftende Hülle voluminöser gemacht werden, als es an sich ist, und darin erblicke ich einen Theil der Bedeutung der Corona (des Eiepithels, Waldeyer).

Eine andere Aufgabe der Corona besteht wahrseheinlich darin, dass durch sie d. h. durch die Umformung der Discus selber, welche 
die Erscheinung der Corona bedingt, das Ei in seiner Stellung im inneren des Follikels gelockert wird, so dass nunmehr ein leichter Druck oder Anstoss genügt, dasselbe aus seinem Lager zu lösen und aus dem Follikel zu entfernen.

Das beste Mittel schöne und zweifellose Präparate von so ungewandelten Zellen der Corona und der "brides ovariques" Coste zu bekommen, ist die Anwendung von starker Salpetersäure (bis zu 50\%) mit nachträglicher Färbung in Alauncarmin.

Die excentrische Stellung des Keimbläschens fällt gewöhnlich mit der Volumzunahme desselben und mit einer Veränderung seiner Form, die dabei rom rundlichen ins ovale iubergeht, zusammen. Dieses Zeichen der Reife (Purkinje, K. E. v. Baer) tritt schon sehr früh auf und ist nicht ganz characteristisch. Es kann sich nämlich auch an Eiern finden, welche von nicht brïnstigen Thieren stammen. Man constatirt dasselbe gewöhnlich in grossen Follikeln vor dem Eintreten der Brunst, am Ende der Schwangerschaft und in den ersten Tagen nach dem Wurfe, wenn noch keine Copulation stattgefunden hat.

Die excentrische Lage des Keimbläschens ist daher nicht als ein Zeichen der vollkommenen Maturität des Eies zu betrachten.

Diejenige Eiform, bei der das Keimbläschen mit der Zona in Beriihrung kommt (Figur 4 und 5 Holzschnitt I) stellt schon ein sichereres Zeichen der vollkommenen Reife des Eies dar. Ich beobachtete diese Erscheinung bei Kaninchen $61 / 2-7$ Stunden ${ }^{1}$ ) und $9 \frac{1}{2}$ Stunden nach der Copulation und bei Meerschweinchen 12 Stunden nach dem Wurfe (die Zeit der Copulation war hier nicht genau ermittelt).

In anderen Fällen, wo ich diese Erscheinung constatiren konnte, handelte es sich um Kaninchen, die vor 13 und 17 Stunden, und um Meerschweinchen, die 2 und 9 Stunden vorher geboren hatten und um ein Meerschweinchen im Anfange der Brunst. In allen diesen 5 Fällen hatte eine Copulation nicht stattgefunden, obgleich der Bock zugelassen worden war und die geschlechtliche Erregung daher wahrscheinlich nicht mangelte.

Das Keimbläschen hat in diesem Stadium ein anderes Aus-

1) Das Präparat stammt aus dem Ende des Jahres 1880 und ist bis jetzt gut erhalten. (Osmium, Müller'sche Flüssigkeit.) 
sehen und eine andere Beschaffenheit als früher. In erster Stelle ist hier die Abwesenheit des Keimfleckes zu erwähnen.

Nach meinen Beobachtungen beginnt dieser Process mit dem Auftreten mehrerer kleinerer Flecke von derselben Lichtbrechung und soustigen Beschaffenheit, wie der ursprüngliche Keimfleck. Diese Flecke liegen dicht neben dem letzteren und dieser selbst erscheint kleiner als frther. Anfangs liegen diese Flecke nahe bei einander in der Form eines Häufchens (Holzschnitt I. Fig. 1 u. 2),

1.

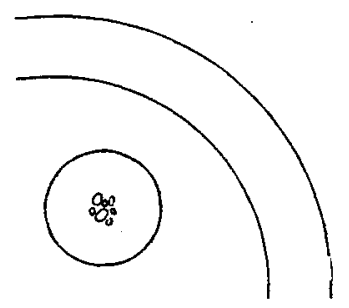

2.

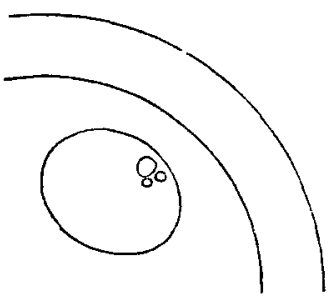

3.

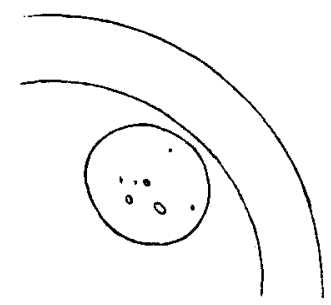

5.
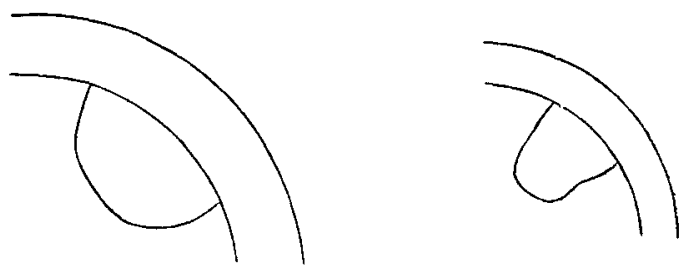

Erklārung zu Holzschnitt I.

Veränderung des Keimbläschens am reifenden Ei.

1) Kaninchen 1 St. 50 M. nach der Copulation.

2) Kaninchen 9. Tag nach der im Anfange unterbrochenen Schwangerschaft; wahrscheinlich gleich vor dem Auftreten der Brunst.

3) Kaninchen $18 \mathrm{St}$. nach dem Wurfe; ohne Copulation.

4) Kaninchen 2 Tage nach dem Gebären; ohne Copulation.

5) Meerschweinchen später als 9 Stunden nach dem Wurfe; ohne Copulation.

Alle Figuren nach den mit Osmiumsäure fixirten Eiern gezeichnet. Camera lucida Milne-Edwards, modificirt von Malassez (Hartn. Sept. VII Oc. 3. Schiefe Ebene.) 
später aber sind sie im ganzen Keimbläschen zerstreut und werden noch kleiner, so dass sie kaum bemerkbar bleiben (Fig. 3). Im folgenden Stadium (Fig. 4 und 5) ist mir keine Spur mehr von Keimflecken zu finden gelungen.

An den reifenden Eiern der Fische hat schon A uerbach (Organologische Studien H. 1. S. 156 u. f.) zahlreiche Keimflecke bemerkt. Anfangs hielt er dieselben sämmtlich - die Zahl reicht in die Hunderte - für Theilungsproducte des ursprünglichen Keimflecks, später ist er zu der Ueberzeugung gekommen, dass nur ein Theil der kleinen Körperchen durch die Theilung von dem ersten Keimflecke abgeleitet werden könnte; die übrigen aber frei aus der Substanz des Keimbläschens entstehen müssten. So weit ich den Vorgang am Säugethierei verfolgen konnte, machte derselbe mir eher den Eindruck eines successiven Zerfalles des ursprünglichen Keimflecks in immer kleinere Stückchen, welche schliesslich in der Substanz des Keimbläschens verschwinden. Es steht dieses in Uebereinstimmung mit der Beobachtung, dass die Nucleolen auch der übrigen Zellen des Organismus vor der beginnenden Theilung schwinden. (Vgl. u. a. die Arbeiten von Flemming, dieses Archiv.) Fische habe ich nicht untersucht, will also hiermit keineswegs über Auerbachs Angaben ein Urtheil ausgesprochen haben. Auch Hertwig bei Nephelis und Bütsehli bei Aphis beobachteten Theilung des Keimfleckes in zahlreiche Fragmente. Kölliker fand bei Ascaris dentata schon im Jahre 1843, dass der Keimfleck wahrscheinlich früher als das Keimbläschen verschwindet; neuerdings bewiesen Kleinenberg bei Hydra u. van Beneden bei Asteracanthiou rubens die regressive Metamorphose am Keimflecke und dessen Theilung in mehrere Fragmente, die später verschwinden.

1.

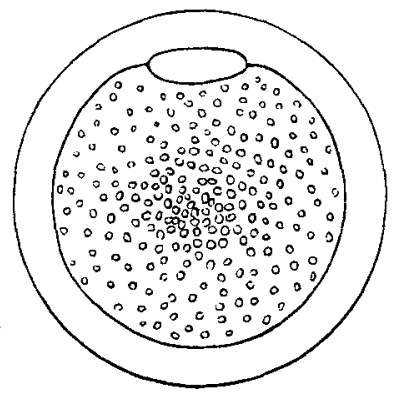

2.

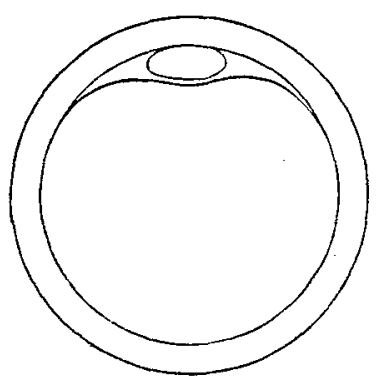

Erklärung zu Holzschnitt II.

Austreten des Keimbläschens; Bildung des ersten Richtungskörperchens.

Meersehweinchen 10-18 St. nach dem Wurf; Copulation nicht beobachtet. Nach den frisrhen Präparaten mittelst Camera lucida gezeichnet. 
Die Substanz des Keimbläschens erscheint an frischen Präparaten homogen und ziemlich stark lichthrechend. Auch die Form des Keimbläschens wird dabei verändert. Gewöhnlich ist es einfach abgeplattet (Holzschnitt II, 2) oder hat eine Gestalt wie sie in Fig. 4 u. 5 Holzschn. I abgebildet ist; endlich hat es ganz unregelmässige faltige Conturen (cf. Fig. 2. Taf. IX). Wahrscheinlich ist ein Theil seiner Substanz, und zwar hauptsächlich flüssige Bestandtheile (Kernsaft nach O. Hertwig), in den Dotter hineingetreten.

Das weitere Sckicksal des Keimbläsehens ist sebr innig mit den anderen wichtigen Vorgängen bei der Reifung des Eies verbunden, namentlich mit dem Auftreten der Richtungskörperchen.

Meinen Beobachtungen nach stammt das erste Richtungskörperchen direkt vom Keimbläschen (Oellacher). Ich möchte hier erst eine diesbezügliche Beobachtung nach meinen Protokollen anführen, ehe ich in der Schilderung weiter gehe.

Beobachtung I. Ein Meerschweinchen gebar am I. III. zwischen $81 / 2$ Uhr Abends und 5 Uhr Morgens. Eins der jungen lebte bis Abends 8 Uhr und schien ganz reif zu sein. Eine Copulation hatte nicht stattgefunden, obwohl der Bock zugelassen worden war. Um 3 Uhr Nachmittags wurde das linke Ovarium exstirpirt. Zwei Follikel waren sehr gross. Das berausgenommene sogleich frisch ohne Zusatz untersuchte Ei bot das Bild von Fig. 1 Holzschnitt II dar. Man sieht, dass das Keimbläschen dicht der Zone anliegt, abgeflacht und von homogenem Aussehen ist. Die grösseren dunklen Dotterkugeln sind im Centrum des Dotters mehr zusammengehäuft. Einige Minuten später, nach Zusatz von $0,6 \%$ pro $\mathrm{ClNa}$-lösung erschienen sie im ganzen Eie zerstreut (Ei abgestorben?). Das Keimbläschen wurde dabei etwas blasser; dann blieb es ohne Veränderungen während einer 2 stündigen Beobachtung auf dem heizbaren Objekttische. Das aus einem anderen Follikel, ungefähr 5 Minuten später entnommene $\mathrm{Ei}$ ist auf Fig. 2 Holzschn. II dargestellt. Man sieht ein deutliches grosses Richtungskörperchen von der Form und Grösse des in der vorigen Figur abgebildeten Keimbläschens; nur scheint es etwas dicker und zu gleicher Zeit kürzer zu sein. Der Dotter ist an der Stelle des ausgetretenen Richtungskörperchens von der Zona etwas abgedrängt, so dass das Richtungskörperchen in einer Delle des Dotters zu liegen scheint. Eine strahlige Figur ist im Dotter nicht bemerkbar. Ein aus dem anderen Ovarium eine halbe Stunde später entnommenes Ei war dem zweiten Eie ganz gleich. Die frischen Präparate wurden sogleich mit der Camera lucida gezeichnet. Professor Waldeyer hat die Präparate auch im frischen Zustande gresehen und dabei an dem Richtungskörperchen des zweiten Eies einen kleinen Fortsatz bemerkt, der seine Form derart veränderte, als ob es sich um amöboide Bewegungen des betreffenden Richtungskörperchens handelte (Hens en). 
Die zwei ersten Eier dieser Beobachtung stellen evident zwei successive Stadien eines und desselben Processes dar - den Austritt des modificirten Keimbläschens und die Bildung eines Richtungskörperchens aus demselben.

In einem anderen ähnlichen Falle bei einem Meerschweinchen mit Symptomen der Brunst, habe ich an einem und demselben Eie ganz dasselbe beobachten können. 'Bei der ersten Untersuchung: sah man ein abgeplattetes Keimbläschen dicht der Zone anliegen, dann aber nach einigen Momenten, die nöthig waren, um das Deckgläschen mit Oel- zu umranden, stellte das Präparat schon das Bild der Figur 2 Holzschnitt II dar. Nach geschehener Umrandung, welche mit aller Sorgfalt ausgefiuhrt wurde, war an dem Eie keine Spur irgend einer Druckeinwirkung wabrzunehmen, so dass ich nicht annehmen kann, dass hier das Keimbläschen künstlich ausgepresst worden wäre. Zu dieser Beobachtung ist ausserdem notirt, dass das frisch ausgetretene Richtungskörperchen einige glänzende Pünktchen oder vacuolenartige Gebilde einschloss. An den anderen Eiern von demselben Ovarium fand ich keine Spur weder vom Keimbläschen noch vom Richtungskörperchen. Eine weitere Präparation dieser Eier so wie Lageveränderungen derselben auf dem Objectglase habe ich leider nicht ausgeführt.

Einen ähnlichen Befund lieferte mir noch ein Meerschweinchen mehr als 12 Stunden nach dem Werfen. Die Zeit der Copulation war nicht genau notirt, aber die Spermatozoiden wurden schon in den Tuben gefunden.

Auch bei einem Kaninchen $91 / 2$ Stunden nach der Copulation hatte ein Ei ein grosses Richtungskörperchen, das dem Aussehen nach sehr dem abgeplatteten nahe zur Zona gerickten Keimbläschen der Fig. 2 Holzsehn. II ähnlich war, nur mit dem Unterschiede, dass es etwas kleiner schien. Dies fällt sehr ins Auge, besonders wenn man es mit demselben Stadium beim Meerschweinchenei vergleicht. An einem anderen Eie aus demselben Eierstocke wurde ein genau im Momente des Austretens begriffenes ähnliches Richtungskörperchen beobachtet. Ein Theil desselben schien noch im Dotter befindlich, während der andere schon aussen war und sich dicht unter der Zona in einem flachen Grübchen am Dotter befand. In beiden Eiern war keine Strahlenfigur bemerkbar. An dem dritten Eie aus demselben Eierstocke wurde weder ein Keimbläschen, 
noch ein Richtungskörperchen gesehen; das $\mathrm{Ei}$ war aber nicht vortheilhaft präparirt.

Zur Bestätigung dieser Beobachtungen können auch die Tubareier, sehr kurz nach ihrem Austritte aus dem Eierstocke dienen. So sieht man an Fig. 8 (Meerschweinchen) ein der Form und der Grösse nach dem Keimbläschen entsprechendes Richtungskörperchen. In einer anderen Beobachtung hatte ein Tubar ei von Meerschweinchen 6 St. nach der Copulation etwa ein eben so grosses Richtungskörperchen, aber von ganz unregelmässiger Form, so dass es wie ein in amöboider Bewegung begriffener Körper aussah. In einem anderen Eie aus demselben Tuba war ein eben so grosses Richtungskörperchen von Bisquitform, wie in Theilung begriffen, aber ohne karyokinetische Figuren zu sehen.

Alle diese Beobachtungen lassen kaum einen Zweifel daran aufkommen, dass bei der Bildung der Richtungskörperchen, wenigstens des ersten derselben, das Keimbläschen einen direkten Antheil nimmt. Es ist ferner dadurch festgestellt, dass letzteres sich vorher sehr beträchtlich verändert, dass namentlich der Keimfleck verschwindet und dass eine Umwandlung aus einem bläschenförmigen $\mathrm{Za}$ stande $z \mathfrak{u}$ einem homogenen protoplasmaähnlichen Klümpchen stattfindet, der active amöboide Bewegungen ausfübren kann.' Die letzte Erscheinung so wie eine gewisse Volumabnahme, die besonders beim Kaninchen bemerkbar ist, legen die Vermuthung nahe, dass dabei ein Uebergang einiger Bestandtheile des Keimbläschens, und zwar am wahrseheinlichsten der flussigen Bestandtheile, in den Dotter stattfindet. Mit Hülfe dieser letzteren Vermuthung wird die schwer erklärbare Erscheinung, dass eine der wichtigsten Zellen des Organismus, gleich vor dem Eintritte einer der wichtigsten Zellenfunctionen, - der Zellvermehrung, - ihren wichtigsten Theil - den Kern - verliert, verständlicher. Uebrigens ist damit die eigentliche Bedeutung der Richtungskörperchen noch nicht erklärt. Vielleicht werden die herrschenden Ansichten darüber, nämlich, dass die Richtungskörperchen keine Rolle bei der weiteren Entwicklung des Embryo spielen, was sich auch in dem von Fol gegebenen Namen ,corpuscules de rebut" ausspricht, überhaupt nicht festgehalten werden können. Vielleicht wird man später za der Einsicht gelangen, dass die Richtungskörperchen der Säugethiere, wenigstens das erste derselben, keine completen Homologa der Richtungskörperchen der niedern Thiere sind, wo die schönen 
und genauen Untersuchungen von O. Hertwig, Fol und Anderen über Echinodermen und ältere von $\mathrm{Ch}$. Robin über Hirudines ganz andere Entstehungsweisen derselben erwiesen haben.

Die von mir gegebene Beschreibung des Schwundes des Keimbläschens und der Bildung des Richtungskörperchens weicht bekanintlich von den Angaben der meisten anderen Forscher über diese Erscheinung bei den genau untersucbten niederen Thieren, so wie von E. van Beneden's Angaben über Kaninchen ab. Unsere Beobachtungen sind darin übereinstimmend mit dem letzgenannten Forscher, dass van $B$ en eden neben dem Keimfleck auch mehrere "Pseudonucleolen“ in ganz reifen Keimbläschen bemerkte. Auch die Annäherung der letzteren an die Peripherie des Dotters und die Berührung des Dotters mit der abgeflachten Seite des Keimbläschens haben wir beide in ähnlicher Weise gesehen. Weitere von van Beneden beschriebene Erscheinungen, wie Bildung der lentille cicatriculaire, plaque nucléolaire, corps nucléoplasmique und corps nucléolaire, konnte ich aber nicht wahrnehmen, ebensowenig wie B a lbia n i, der auch neuerdings diese Angaben von va $\mathrm{n}$ B en e d en zu bestätigen suchte. Weiterhin sind unsere Beobachtungen wieder in Uebereinstimmung, namentlich darin, dass der Moment des Schwundes des Keimbläschens mit dem Auftreten des Richtungskörperchens zusammenfällt, und dass ein Theil der Substanz des Keimbläschens direkt in das Richtungskörperchen übergeht. Nur die gleichzeitige Bildung von zwei Richtungskörperchen aus dem Keimbläschen habe ich niemals beobachtet. Für Meerschweinchen, wo das Ei viel kleiner ist, dagegen das Richtungskörperchen grösser als bei Kaninchen, halte ich das sogar für unmöglich und scheint mir wenigstens für dieses Thier das zweite Richtungskörperchen eine ganz andere Entstehungsquelle, als das erste Richtungskörperchen zu haben; wahrscheinlich dieselbe, wie sie neuerdings für Echinodermata angegeben ist. Die Differenz zwischen beiden Richtungskörperchen habe ich besonders gut aus dem in Fig. 10 dargestellten Präparate notirt, wo eins derselben ganz klar, homogen, das andere hingegen feinkörnig und mit amöboiden Fortsätzen erschien. Nur erkläre ich mir diese Differenz anders als van Beneden; Einige in der Litteratur befindliche Angaben, dass auch ein ganz reifes Säugethierei, ja sogar ein in der Tube gefundenes noch Keimbläschen haben könne (Bischoff, v. Beneden 1870), müssen als ein Irrthum betrachtet werden. In diesen Beobachtungen sind mit Keimbläschen ganz andere Gebilde - meistens der Eikern - verwechselt worden. Zu dieser Kategorie gehört auch wahrscheinlich die Fig. 148 in Kölliker's Entwickelungsgeschichte, II. Aufl., copirt nach $\mathrm{H}$ en s en, wo unter $\mathrm{Vg}$. der Spermakern als Keimbläschen bezeichnet ist.

Active Contractionserseheinungen des Dotters treten auch als eine Reifungserscheinung in verschiedenen Formen auf. In erster Linie muss hier die leichte Contraction an der Stelle des Austretens des 1. Richtangskörperchens am Eipole genannt werden (Holzschnitt II Fig. 2). Man sieht hier eine leichte Ver- 
tiefung an der Oberfläche des Dotters, in der ein Theil des Richtungskörperchens liegt und beiderseits davon auf eine gewisse sehr kleine Strecke einen am lebenden Ei mit klarer Flüssigkeit gefuillten Raum (perivitelliner Raum). Die Compression des Dotters an dieser Stelle scheint mir theils passiver Natur zu sein.

Etwas Anderes ist es, wenn der Dotter fast an seiner ganzen Peripherie von der Zona abgelöst erscheint und nur an wenigen Punkten die Zona beriihrt, wie es schon von Bis ch of $f$ und Anderen am Tubarei der Säugethiere vielfach beschrieben worden ist (cf. Fig. 10 u. and.). Dabei nimmt bekanntlich das Volum des Dotters beträchtlich $a b$, bis anf ungefähr ein Drittel des ursprünglichen. Die Conturen des so contrahirten Dotters sind gewöhnlich von kreisähnlichem oder ovalem Umrisse, manchmal jedoch auch eingebuchtet oder von sonderbarer unregelmässiger Form, wie es Hensen l. c. in Fig. VIII Taf. 6 abgebildet hat und wie ich es auch mehrere Male gesehen habe; diese letzteren Bilder erinnern sehr an amöboide Bewegungen. Solche Contractionen des Dotters sah ich niemals an dem Ovarialei und scheint mir die Vermuthung ganz berechtigt, dass eine active Contraction, wenigstens wenn sie in sehr ausgeprägter Form auftritt, schon als eine der nächsten Folgen der stattgefundenen Imprägnation zu betrachten sei.

Uebrigens habe ich auch einen bis zur Hälfte des Volumens contrahirten Dotter einmal bei einem Meerschweinchenei aus der Mitte der Tube mehr als 12 Stunden nach dem Wurfe gesehen. Hier konnte aber kein einziges Spermatozoon im ganzen Genitalkanal, der sorgfältigsten Untersuchung ungeachtet, nachgewiesen werden. Die andere Tube dieses Thieres wurde ungefäbr 12 Stunden später excidirt und ein Ei mit zwei grossen Segmenten und mehreren sehr kleinen darin gefunden. In diesem Falle scheint eine hochgradige Contraction des Dotters, und sogar ein Anfang von Segmentirung, letzterer Process aber in abnormer Weise, ohne Copulation, eingetreten zu sein, ein Vorgang, der somit als ein parthenogenetischer erklärt werden müsste.

$\mathrm{Zu}$ den activen Contractionserscheinungen muss ich noch ein dreimal von mir gesehenes Phänomen rechnen. An einem Meerschweinchenei, 16 Stunden nach der Begattung, sah ich den mässig contrahirten ovalen Dotter an einer Spitze seines scharf abgegrenzten Contours einen abgerundeten conischen klaren Fortsatz bilden, der mich lebhaft an den Cone d'attraction von Fol erinnert hat. 
Mehrere Spermatozoen wurden in der Tube nachgewiesen, keins aber_in der nächsten Ungebung des Eies gesehen. Die Conturen des Conus änderten sich eine Zeit lang augenscheinlich, und kann Professor Walde yer die Genauigkeit der Beobachtung mit zwei von ihm selbst gemachten Zeichnungen bestätigen (Holzschnitt III).

Fig. 1. Richtungskörper (?)

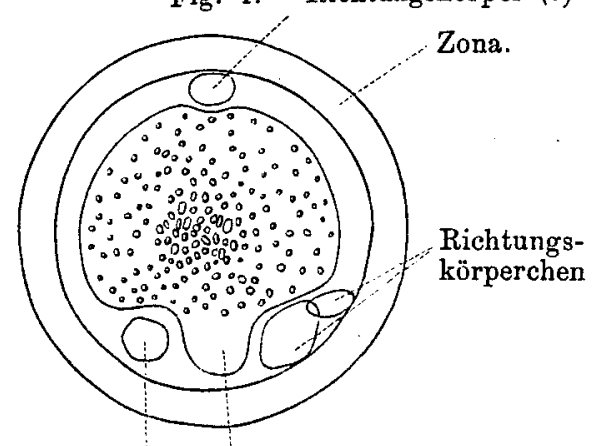

Richtungskörper. Klarer Dotterhügel.

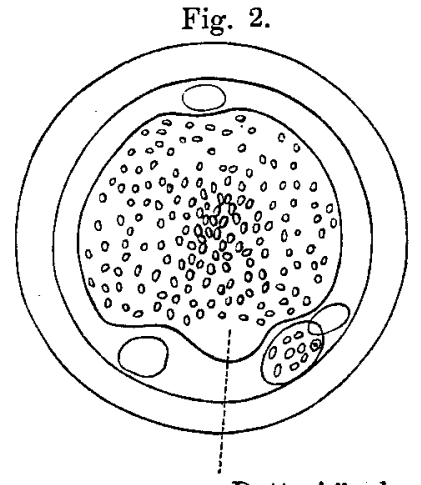

Dotterhügel.

Erklärung zu Holzschnitt III.

Eier vom Meerschweinchen 16 Stunden post Coitum in der Mitte der Tube gefunden. - Fig. 2 einige Momente später gezeichnet von demselben Präparate als Fig. 1.

Nach der Fixirung mit Osmiamsäure schwand der Conus. Das Ei bot ausserdem noch eine andere Eigenthümlichkeit, nämlich das Vorhandensein von 4 Körpern, die gar nicht von Richtungskörperchen unterschieden werden konnten. Eine solche Zahl von Richtungskörperchen wurde bis jetzt niemals meines Wissens beim Meerschweinchen beobachtet. Bei Kaninchen haben Coste sowie Bischoff (Kaninchenei, Tab. I Fig. 6) schon 5 Richtungskörperchen beschrieben.

Eine ähnliche Beobachtung habe ich noch einmal zwei Jahre später an einem Meerschweinchen 6 Stunden nach der Copulation machen können. Zwei Eier wurden in der Mitte der sehr langen Tube gefunden; an einem derselben waren noch einige Zellen der Corona auf der Zona und ein sehr grosses bisquitförmiges Richtungskörperchen zu sehen. Der Dotter war mässig contrahirt und berührte nur in einem Punkte die Zone. Auf der entgegengesetzten Seite des Dotters, gleich unter dem Richtungskörperchen, sah ich einen ebensolchen Conus unter meinen Augen sich bilden und dann sogleich, aber sehr langsam, wieder verschwinden. Auch in diesem Falle war kein Spermatozoon in der Nähe des Eies zu sehen, so 
wie kein Pronucleus im Irnern des Dotters, so dass das Ei mir noch unbefruchtet zu sein schien. Im dritten Falle dagegen (Meerschweinchen aus der Mitte der Tube 131/2 St. nach der Copulation) waren in der nächsten Nachbarschaft des Eies drei todte Spermatozoen bemerkbar.

In diesen drei Fällen konnte man durch direkte Beobachtung die amöboiden Bewegungen des Dotters, constatiren (cf. Hensen, l. c. p. 221 , Balbiani). Dagegen vermochte ich niemals dié Bischoff'sche rotirende Bewegung des Dotters zu sehen, ungeachtet dass ich mehrere Male Gelegenheit gehabt habe, die Eier von Meerschweinchen in dem von Bisch off abgebildeten Stadium (Meerschweinchen, Tab. I Fig. 4), in welchem er dieses Phänomen beobachtete, zu untersuchen und zwar manchmal unter ganz vorzüglichen Bedingungen der Beobachtung.

Starke und rasche Volumveränderungen des Dotters, sowie seine amöboiden Bewegungen sprechen gegen die Existenz einer besonderen Dottermembran (membrane vitelline), wie sie von van Beneden bis nenerdings für das reife Ovarialei des Kaninchens angenommen wird. Ich suchte vergebens mehrere Male nach einer solchen Membran, konnte mich jedoch niemals in unzweifelhafter Weise von ihrer Existenz überzeugen. Das Ei in Fig. 10 spricht besonders gegen die Annahme der Dottermembran. Auf der ganzen Oberfläche des Dotters konnte man zahlreiche kleine, aber ganz deutliche lappige hyaline Fortsätze constatiren. Das Ei wurde ganz frisch und ohne Zusatz untersucht. Es stammte von einem Meerschweinchen 28-29 Stunden nach der Copulation.

$\mathrm{Zu}$ den nicht unwichtigen Reifungszeichen gebört auch das Auftreten von Dotterkugeln im Dotter, welche grösser und viel $\mathbf{d}$ u nkler als die Körnchen des tibrigen Protoplasmas erscheinen "). Sie vertheilen sich in besonderer, meist regulärer Weise im Dotter, indem sie sich im Centrum desselben anhäufen (medullare und corticale Substanz von van Beneden, cf. Fig. 9).

Diese Trennung des Dotters in zwei Schichten kann man auch nach der Dottercontraction, ja sogar nach der Imprägnation beobachten.

Ganz characteristische zu derselben Art der Erscheinungen gehörende Bilder habe ich an reifen Ovarialeiern bei drei Kaninchen 8-11/2 Stunden nach der Copulation beobachtet. Die dunkleren Dotterkägelehen bildeten mehrere Häufchen von unregel-

1) Besonders gross sollen sie den Zeichnungen von van Beneden und Julin nach bei den Fledermaus-Eiern sein. 
mässiger Form und ungleicher Grösse, die im ganzen Dotter ohne jegliche Ordnung zerstreut waren und der Dotter hatte dabei ein höchst characteristisches fleckiges Aussehen. Solche Eier haben bekanntlich B isch off (Kaninchenei, Taf. I Fig. 2) und Coste gesehen und abgebildet, und zwar Coste von einem vollkommen reifen Orarialei 10 Stunden nach der Copulation ${ }^{1}$ ). Ich habe im Ganzen mehr als 10 solcher Eier beobachtet und mehrere davon Professor Wal d ey er demonstrirt. Immer waren dabei auch andere unzweifelhafte Reifungserscheinungen, als Anwesenheit der Richtungskörperchen $u$. a. vorhanden, und manchmal waren schon einige Follikel desselben Eierstockes geplatzt (ef. Beobachtung 5 unten), so wie in der citirten Beobachtung von Coste. Auch an den eben in die Tube eingetretenen Eiern war diese sonderbare Vertheilung der Dotterkügelchen noch bemerkbar. Ebenso sah ich an den.mit Osmium fixirten Eiern das Bild unverändert.

Ich bin geneigt die ebenbeschriebene Erscheinung, als eine der normalen Reifungserscheinungen und zwar eine der letzten der Reihe nach zu betrachten.

Dotterkern im Ovarialei. Bei drei Kaninchen habe ich den Dotterkern im Ovarialei (Balbiani) beobachtet und zwar zweimal an reifenden Eiern mit gleichzeitig existirenden, aber peripher gelegenen Keimbläschen und einmal an einem ganz reifen Eie 8 Stunden nach der Copulation. Ich halte es für nothwendig alle diese drei Fälle hier kurz zu protocolliren:

Beobachtung 2. Einem Kaninchen wurde am 6. Tage der Schwangerschaft das rechte Uterushorn exstirpirt, am 7. Tage das linke. Acht Tage später starb das seit der Zeit der Operation vom Männchen isolirte Thier und bei der Obduction wurde eine grosse abgekapselte Abscesshöhle an der Stelle des exstirpirten linken Hornes und des linken Ovariums gefunden. Das rechte Ovarium sah vollkommen gesund aus und entbielt $\mathbf{5}$ grosse prall gespannte Follikel. In einem von den untersuchten Eiern (Fig. 2) war das Keimbläschen derartig verändert, dass über sein nahe bevorstehendes Verschwinden kein Zweifel sein konnte: es war ganz an der Peripherie des Dotters gelegen, schloss zwei grössere Keimflecke und mehrere Nebennucleolen ein und seine Contouren waren unregelmässig, fast von faltigem Aussehen. Nahe dem Centrum dieses reifenden Eies lag, ziemlich tief in den

1) In der Erklärung der Bi s choff'schen Zeichnungen ist nichts weiteres als "Ovarialei" gesagt. An meinen Präparaten waren die Flecke niemals von so gleicher Form, Grösse und Färbung, als das auf der Bischoff'schen Zeichnung der Fall ist. 
Dotter eingesenkt, ein deutlicher kernähnlicher Körper, über dessen Grösse und Form die Fig. 2, welche nach einem mit Osmium und Mülller'scher Flüssigkeit behandelten Präparate gezeichnet worden ist, eine richtige Vorstellung giebt. Die Substanz dieses Kernes war äusserst feinkörnig. Keine Spur eines Kernkörperchens konnte ich am frischen Präparate bemerken. - Eins von den übrigen aus demselben Eierstocke entnommenen Eiern war ohne Keimbläschen, in zwei anderen waren ebenso an der Peripherie des Dotters grosse ovale Keimbläschen, aber kein Dotterkern zu constatiren. Die Elemente der Corona radiata waren noch nicht vollkommen faserartig beschaffen.

Beobachtung 3. Das zweite Mal habe ich den Dotterkern genau im Centrum eines Ovarialeies bei einem Kaninchen, das 13 Stunden vorher geboren hatte, sich aber nicht begatten liess, wahrgenommen. Das Keimbläschen war ebenso wie bei der ersten Beobachtung ganz nahe der Peripherie gelegen, schloss keinen deutlichen Keimfleck mehr ein und sah etwas faltig aus. Die Contouren des Dotterkernes schienenmir während der Untersuchu ng sich zuverändern. Das Ei wurde mehr als 3 Stunden auf dem heizbaren Objecttische in einer Ranvier'schen feuchten Kammer beobachtet, bot aber keine weiteren Veränderungen dar.

Beobachtung 4. Im letzten Falle handelte es sich um ein Weibchen, das in meinem Käfige geboren hatte, seine Jungen säugte und 25 Tage nach der Geburt sich begatten liess. 8 Stunden nach der letzten Copulation wurde ein Ovarium mit 3 grossen prall gefüllten Follikeln exstirpirt. An allen drei Eiern wurde eine prachtvolle Corona, radialgestreifte Zona, Abwesenheit des Keimbläschens und fleckiges Aussehen des Dotters constatirt. Zwei von diesen Eiern zeigten ausserdem am Eipole contrahirten Dotter und ein grosses Richtungskörperchen. In einem von diesen letzten Eiern fand sich ein Dotter kern. Wie aus dem nach der Camera lucida-Zeichnung angefertigten Holzschnitte IV ersichtlich, war er excentrisch gelegen, etwas kleiner als das Keimbläschen eines reifen Eies, von schwach glänzender homogener Substan

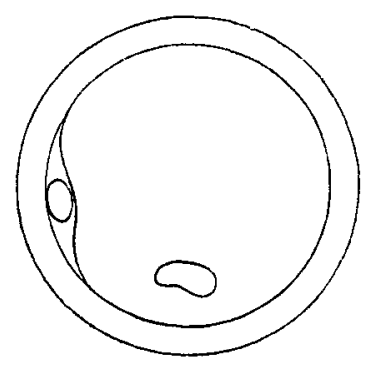

Erklärung zu Holzschnitt IV.

Kaninchen 8 St. nach der Copulation. Richtungskörperchen, Dotterkern. - Halbschematische Zeichnung. 
und unregelmässiger Form. Während seiner Beobachtnng durch Professor Waldeyer (heizbarer Objecttisch) führte er amöboide $\mathbf{B} e w e g u n g e n$ aus. - Die 1 Stunde später aus dem anderen Eierstocke entnommenen zwei Eier waren von ganz ähnlicher Beschaffenheit, nur waren weder Richtungskörperchen, noch Dotterkerne zu bemerken.

Die angeführten Beobachtungen über den Dotterkern sind natürlich ungentigend, um irgend welche sichere Schliusse wie über die Enstehungsweise, als auch ïber die Bedentung dieses Gebildes zu ziehen. Eine Vermuthung aber halte ich für sehr plansibel, nämlich, dass der hier sogenannte Dotterkern nichts anders sei, als der später näher zu besprechende Eikern. Dafür spricht seine Form, Grösse, die Beschaffenheit seiner Substanz und die Fähigkeit amöboide Bewegungen auszuführen. Wenn diese Vermuthung bestätigt werden sollte, so wäre sein so zeitiges Auftreten, früher als die Begattung erfolgt und unabhängig von ibr, ja sogar bei Eiern, an welchen das Keimbläschen noch nicht geschwunden ist, und andere sichere Zeichen der Reife noch fehlen, eine höchst interessante Erscheinung. Das Keimbläschen hätte dann an der Bildung der ersten Segmentkugel keinen direeten Antheil, was auch mit meinen Beobachtungen über den Schwund des Keimbläschens vollkommen übereinstimmt ${ }^{1}$ ).

Ob jedes reife Ovarialei einen Dotterkern hat, und ob derselbe nur wegen der Undurehsichtigkeit des Dotters so selten sichtbar ist, kann nur durch zahlreiche weitere Untersuchungen entschieden werden. Mir scheint diese Vermuthung nicht unmöglich zu sein.

Am Ende dieses Capitels will ich noch eine Beobachtung anführen, die ein gutes Beispiel eines vollkommen reifen Ovarialeies des Kaninchens betrifft und auch in manchen anderen Beziehungen nicht ohne Interesse ist.

Beobachtung 5. Ein Kaninchen gebar ein einziges, sehr grosses aber todtes Junges 5 h. $37^{\prime}$ Abends. 2 Stunden 23 Minuten später, also um $8 \mathrm{Uhr}$ Abends, fand die erste Copulation und später noch mehrere ștatt. Die ganze Nacht blieb das Weibchen mit dem Bocke zusammen. Um $6^{3 / 4}$

1) Bekanntlich hat Fol im Gegentheil bei Echinodermen beobachtet, dass der Eikern nur nach dem Schwunde des Keimbläschens und nach der Bildung beider Richtungskörperchen aus dem im Dotter bleibenden Theile des zweiten Amphiaster entsteht. Nach diesen Untersuchungen wäre also die gleichzeitige Existenz des Eikernes und des Keimbläschens bei den Echinodermen eine Unmöglichkeit. 
Morgens Anfang der Aethernarcotisation; um $7 \frac{1}{4}$, als $10 \%$ Stunden nach der ersten Copulation, wurde die Bauchhöhle geöffnet. Auf einem Ovarium sah man 4 frisch geplatzte Follikel und einen sehr grossen trüben röthlich gefärbten geschlossenen Follikel. Am anderen Ovarium befand sich ein frisch geplatzter und ein noch ungeplatzter Follikel genau von derselben Beschaffenheit, wie der eben beschriebene. Das erste Ovarium wurde exstirpirt und die Bauchwunde zugenäht. Das dem grössten Follikel entnommene Ei liess eine sehr schöne vollkommen entwickelte Corona radiata erkennen. Auch die benachbarten Elemente des Discus waren stark faserartig umgebildet und nicht selten mit gegabelten Fortsätzen versehen. Der Eidotter hatte ein fleckiges Aussehen und war nur am Pole contrahirt. In einer hier bemerkbaren Delle befand sich ein einziges sehr grosses Richtungskörperchen, das sehr klare amöboide Formveränderungen wahrnehmen liess. Keine Spur eines Keimbläschens noch irgend welches anderen Kernes konnte wahrgenommen werden. Nach der Präparation des Eies, und zwar nach dèr Abtrennung der Corona, bot die Zona ganz deutliche radiäre Streifung (SehIen ${ }^{1}$ ).

Um $8 \frac{1}{2}$ h. wurde das Thier getödtet und die Bauchhöhle von Neuem eröffnet. Im zurückgebliebenen Eierstocke wurden jetzt $z$ wei frisch geplatzte Follikeln gefunden. Einer von diesen war also während der Untersuchung des ersten Eierstockes geplatzt, d. h. $10^{1 / 4}-11^{3 /}$ Stunden nach der ersten Copulation. Beide Eier wurden nebeneinander in der Tube gefunden, an der Grenze des stark geschwollenen ersten und zweiten Drittheiles dieses Organes. Beide Eier stellten genaue Copien des eben beschriebenen Ovarialeies dar (Corona, fleckiger Dotter, beginnende Contraction desselben und ein grosses Richtungskörperchen). Kein Kern, kein Spermatozoon, keine weitere Dottercontraction war wahrzunehmen. Die Eier schienen noch nicht imprägnirt zu sein. Eines von beiden Eiern hatte somit das erste Drittel der Tube in weniger als 1\%, Stunden durchwandert.

\section{Schlussfolgerungen über Reifungserscheinungen.}

I. Von den Reifungserscheinungen am Säugethier habe ich folgende beobachtet: 1. Corona radiata, 2. peripherisehe Lage des Keimbläschens, 3. Auflösung des Keimfleckes, 4. Schwund des Keimbläschens, 5. Auftreten eines Richtungskörperchens, 6. Beginn der Contraction des Dotters an einem Eipole, 7. amöboide Bewegungen des Dotters, 8. Auftreten von grösseren Dotterkugeln in demselben, 9. fleckiger Dotter, 10. den sogenannten Dotterkern.

II. Sie treten meist sehr spät auf, gewöhnlich erst nach der

1) Sehlen. Arch. f. Anat. u. Phyl. Anat. Th. 1882. H. 1. 
Copulation. Nur die periphere Lage des Keimbläschens, eine nicht stark ausgeprägte Corona und vielleicht auch der Dotterkern können auch ausser der Brunst beobachtet werden; daher kann man diese Zeichen vielleicht als relative unterscheiden, während alle übrigen als absolute Zeichen der Reife zu betrachten sind. Nach dem Auftreten der letzteren verlässt das Ei in kurzer Zeit, manchmal schon in wenigen Minuten, den Follikel.

III. Das erste Richtungskörperchen ist nichts anderes als das herausgetretene veränderte Keimbläschen.

\section{Befrnchtungsvorgänge.}

Das distale Drittel der Tube wird beim Kaninchen und Meerschweinchen vom ausgetretenen reifen Eie rasch, und ohne dass letzteres besondere Veränderungen erlitte, passirt. Erst im mittleren Drittel, 13-17 Stunden nach der Copulation, tritt eine neue Reihe von interessanten Veränderungen auf. Nur in diesem Theile der Tube habe ich das Ei bei. den beiden genannten Species im unzweifelhaften Contact mit Spermatozoen gesehen, und zwar in einigen Fällen wahrscheinlich eben nach der stattgefundenen Imprägnation. Es sei mir erlaubt die betreffenden Beobachtungen hier anzuführen.

Beobachtung 6. Ein Kaninchen hatte am 25. V. zwischen 1 und $6 \mathrm{~h}$. Nachmittags, in welcher Zeit es unbeobachtet geblieben war, 6 Junge geboren. Nach sofortiger Zulassung des Bockes wurde um 61/4 h. die erste Copulation beobachtet und dann noch mehrere. Während der Nacht wurde das Weibchen mit dem Bocke zusammen gelassen. Am 26. V. um 81/2 h. Morgens wurde dem tief narcotisirten Thiere die rechte Tube ausgeschnitten. Auf dem rechten Ovarium waren 3 frische gelbe Körper bemerkbar. Um 8 h. 45', d. h. 141/2 Stunden nach der ersten Copulation wurden drei Eier schon in der Mitte der betreffenden Tube gefunden und mit allen Cautelen beobachtet, doch ist es vielleicht in diesem Falle möglich, dass ein geringer Druck des Deckgläschens stattfand.

Das erste $\mathrm{Ei}$ (Fig. 3) hatte zwei Richtungskörperchen und mehrere Spermatozoen theils ausserhalb der Zone, theils innerhalb derselben gelegen. Die meisten Spermatozoen sind in der Figur nicht mitgezeichnet, so wie auch die Theilung des Dotters in die drei van Bene den'schen Schichten, eine centrale, eine peripherische und eine intermediäre nicht auf der Zeichnung angegeben ist. Zwei Spermatozoen wurden innerhalb der Zona an der Oberfläche des Dotters sich bewegend angetroffen, was auch von Professor Waldeyer 
constatirt wurde. Sie führten länger als eine Stunde lebhafte pendelnde Bewegungen aus und eines derselben bewegte sich auch langsam im Raume voran. Ausserdem wurde schon beim ersten Ansehen des Eies ein merkwürdiger kernähnlicher Körper (S) bemerkt. Er war oval, ganz hell und homogen und erinnerte lebhaft an den stark gequollenen Kopf eines Spermatozoon. Während der Untersuchung schien er sich noch etwas za vergrössern. Um $10 \mathrm{~h}$. 10 M. kam noch ein zweiter Kern (e) in demselben Eie in Sicht. Vorher war er sicher nicht zu constatiren gewesen. Er konnte entweder sich eben gebildet haben, oder er rückte activ ins Beobachtungsfeld aus den tieferen Theilen des Präparates ein. Letzteres scheint mir das wahrscheinlichste, da er auch während der weiteren Beobachtung und der Zeichnung des Präparates sich dem ersten Kerne näherte. Das hat auch der Zeichner, Hr. Wittmaack, bemerkt, der der Angelegenheit völlig unbefangen gegenüberstand. Der zweite Kern war rundlicher als der erste und ausserdem etwas grösser. Er erschien feinkörnig und enthielt ein Paar vocuolenartige Gebilde. - Das zweite Ei (Fig. 4) hat dieselbe Beschaffenheit des Dotters. Zwei dicht nebeneinander liegende Kerne waren in ihm leicht erkennbar. Einer derselben war etwas kleiner und heller als der andere. Während der Beob. achtung, besonders bei der Zeichnung, wurde bemerkt, dass beide Kerne inmer, aber sehr langsam, ihre Contouren veränderten.

Das dritte Ei stellte ein Zwischenstadium der beiden soeben beschriebenen dar. Ein Kern war länglich, fast spindelförmig wie (s) in dem ersten Eie, nur waren beide Kerne nicht so weit von einander entfernt und berührten sich beinahe ähnlich wie im zweiten Eie. Die andere Tube wurde nicht untersucht.

Bevor ich die in dieser Beobachtung bemerkten Erscheinungen zu erklären versuche, halte ich es für besser noch eine andere derartige Beobachtung mitzutheilen.

B eobachtung 7. Ein innerhalb der letzten 24 Tage nicht begattetes Kaninchen. Erste Begattung am 11. IV. um 6 h. 55 M. Abends. Am 12. IV. um 8 h. 45 M. Morgens in der Narcose der Bauchschnitt ausgeführt. Um 9 h. 5 M. d. h. 14 St. 10 M. nach der ersten Copulation wird das erste in der Mitte der Tube, etwas näher zur Fimbrie gefundene Ei unter das Mikroskop gebracht. Die Dotterkügelchen waren unregelmässig im ganzen Dotter zerstreut, an der Zone wurde noch ein Rest des Eiepithels gesehen. Der Dotter (Holzschn. V, A) ist besonders am Eipole contrahirt und im perivitellinen Raume sind zwei Richtungskörperchen erkennbar. Mehrere unbewegliche Spermatozoen befinden sich ausserhalb und innerhalb der Zona. Im Dotter zeigt sich ein körniger Kern (e) und nebenbei ein Körper, der nach seinen Contouren an einen gequollenen Spermatozoenkopf mit einem Theile des nach der Peripherie gerichteten Schwanzes (s) erinnert. Das Ei wurde in einer feuchten Kammer bei $37,5^{\circ}$ aufbewahrt. Um 12 h. sah das Präparat schon anders aus (Holzschnitt V, B). An der Stelle eines Kernes waren zwei nebeneinander gelegene sichtbar und keine Spur des spermatozoenähnlichen Gebildes s (in A) war mehr erkennbar. 
A.

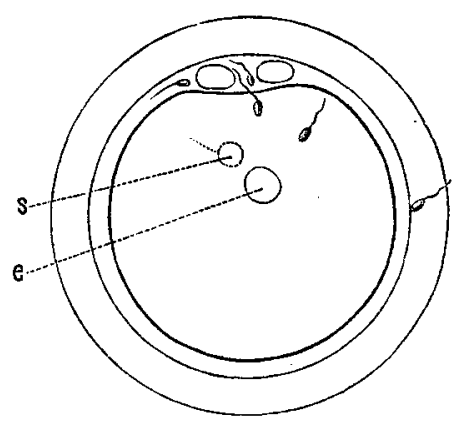

B.

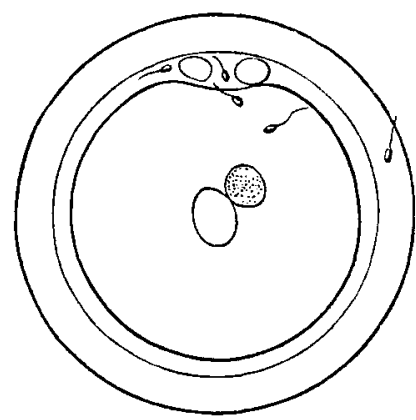

Erklärung zu Holzschnitt V.

Kaninchenei 14 Stunden nach der Copulation. A gezeichnet um $9 \mathrm{~h}$. 20 M.; B dasselbe Ei gezeichnet um 12 h. 5 M. s Spermakern, e Eikern.

Das zweite Ei (Fig. 5) wurde eine Stunde später, also ungefähr 15 St. nach der ersten Copulation, an der entsprechenden Stelle der anderen Tube gefunden. Auf dem entsprechenden Ovarium sieht man ein frisches Corpus luteum und 3 prall gespannte Follikel, von denen einer etwas später, während das Ovarium sich in der erwähnten feuchten Kammer befand, platzte. Auf der Zona sind einige Zellen der Corona noch sichtbar. Dottercontraction viel bedeutender als in dem ersten Eie. Zwei Richtungskörperchen leicht zu erkennen. Die Substanz des Dotters ist, wie im vorigen Falle, in die drei Schichten getheilt und zeigt eine deutliche radiäre Vertheilung der Protoplasmakörnchen. Die Strahlen gehen vom Centrum des Eies aus, wo schon bei dem ersten Blicke ins Mikroscop ein kernartiges Gebilde bemerkt wurde. Bei weiterer sorgfältiger Beobachtung. war es unschwer zu entscheiden, dass dieses Gebilde deutliche und rasche amöboide Bewegungen ausführte. Der Holzschnitt VI gibt eine Vorstellung der verschiedenen Formen, welche das Gebilde während der Beobachtung annahm. Die Veränderungen der Form waren so bedeutend und schnell, dass ich kaum die Zeit hatte, ihre Contouren in einfachen Umrissen mittelst der Camera clara zu zeichnen. (Die Erscheinung wurde einem meiner Collaboranten, Herrn Dr. Usk off, demonstrirt.) Nach einer Viertelstunde wurden die Bewegungen langsamer, doch dauerten sie sicher mehr als 2 Stunden fort. Im Anfange der Beobachtung war es schwer zu bestimmen, ob es sich hier um einen oder mehrere sich amöboid bewegende Kerne handelte. Manchmal schien es, als ob nur ein sich in verschiedenen Richtungen theilender Kern existirte (1,2). Später wurde nebenbei noch ein zweiter kleinerer Kern bemerkt ( 3 und folg.). Weiter konnte man bei einer gegebenen Einstellung des Tubus an der Stelle des grösseren Kerns zwei bis drei kleinere verschieden gelegene einzelne Theile, welche theilweise unklar contourirt waren (auf dem Holzschnitte punctirt), erkennen. Diese Bilder weisen, wie mir scheint, auf die Existenz mehrerer grösserer Isappen, die nur durch schmale Brücken mit einander verbunden waren, hin. Am 
Ende der Beobachtung, wo die Bewegungen viel langsamer wurden, sah man am häufigsten $(8,9,11)$ ein Bild von zwei ungleich grossen Kernen, von denen der grössere eine Vertiefung in der Mitte besass, welche der Form und Lage nacb dem kleineren Kerne entsprach. Der grössere Kern schien gleichsam den kleineren umarmen zu wollen. Diese letzte Form wurde auch nach dem Fixiren des Lies mit Osmium erhalten (cf. Fig. 5).
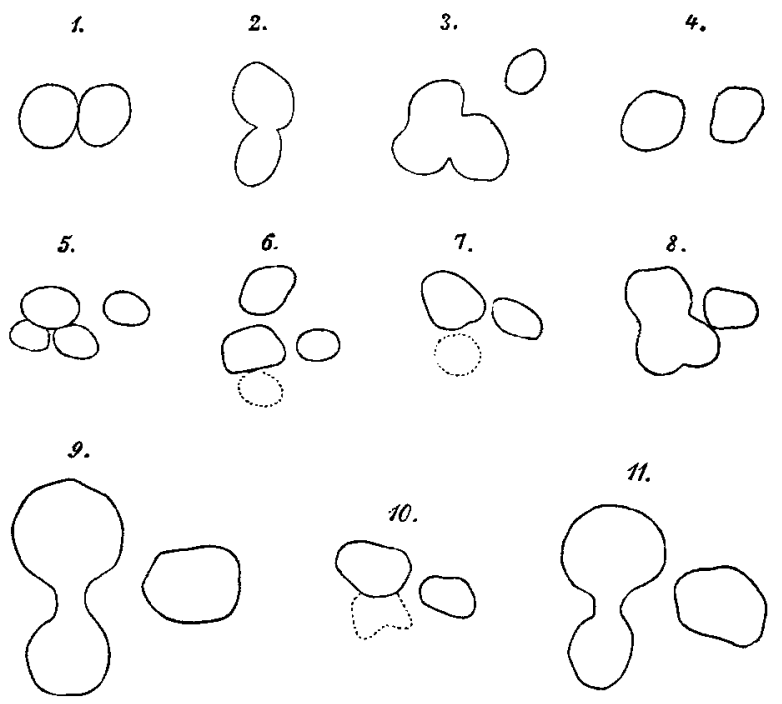

Erklärung zu Holzschnitt VI.

Conjugation der Pronuclei im Tubareie von einem Kaninchen 15 Stunden nach der Begattung (cf. Fig. 5 Taf. IX). Verschiedene successive Phasen der amöboiden Formveränderung. Heizbarer Tisch von Max Schultze. Camera lucida von Milne-Edwards, modificirt von Malassez. - Schiefe Ebene. Hartnack Syst. 3./VII., nur 9 und 11. - 3./X. (Wasser-Immersionssystem). 1. $-4 .-10$ h. $15^{\prime}-10$ h. $20^{\prime}, 5-10$ h. $20^{\prime}, 6-10$ h. $30^{\prime}, 7-10$ h. $50^{\prime}$, 8-11 h. $3^{\prime}, 9-11$ h. $25^{\prime}, 10-11$ h. $50^{\prime}, 11-3$ h

Wenn wir nun die in den Beobachtungen 6 u. 7 enthaltenen Thatsacben zu interpretiren versuchen, so wird es wohl keinem Zweifel unterliegen, die Kerne (s) und (e) als den Spermakern und den Eikern 0. Hertwig's zu deuten. Im Kaninchenei wurden sie schon in der oben citirten vorlänfigen Mittheilung Ed. van Beneden'sund zwar als peripherischer und centraler Pronucleus beschrieben.

Seit dem Erscheinen der Arbeit von O. Hertwig ist schon von mehreren Seiten bewiesen, dass der Spermakern dieses Autors sich in der That aus dem Spermatozoon bildet (Fol, Selenka, Calberla, Kupfer, Salensky, van Bambeke, Flemming 
und And.). In einer neuerdings ersehienenen Arbeit tuber die Befruchtung bei den Fledermäusen bezeichnet auch van Beneden mit $J$ ulin seinen peripherischen Pronucleus als "pronucleus mâl" und den centralen als den "pronucleus femelle".

Auf Grund nun meiner Beobachtungen ( 6 und 7 ) und einiger anderen ähnlicheu so wie nach der Analogie mit anderen Thieren halte ich mich für berechtigt das Entstehen des Kernes (s) aus dem Spermatozoon als sicher anzugeben. In der Beobachtung 6 (Fig. 3) entspricht seine Form einem gequollenen Spermatozoenkopfe. In Beobachtung 7 (Holzschnitt 4) handelte es sich um dieselbe Erscheinung und vielleicht war die Imprägnation noch in in einem früheren Stadium, denn das Spermatozoon zeigte auch noch einen Theil seines Schwanzes; ferner hatte der Dotter noch nicht die für die eben befruchteten Eier characteristische Vertheitheilung der Dotterkigelchen in drei Schichten. In beiden Fällen muss der Spermakern mit gleichem Recht für einen sich rasch verändernden Spermatozoenkopf genommen werden, als es in den citirten Arbeiten über niedere Thiere geschiebt; dort aber war es in manchen Fällen (Fol, Selen $k a$, Calberla) mittelst directer Beobachtung der Imprägnation bei künstlicher Befruchtung festgestellt. Was den Eikern betrifft, so stimmen dit angeführten Beobachtungen mit der oben ausgesprochenen Vermuthung, dass er viel früher, vor der Begattung, vielleicht meist noch im Ovarium, erscheint, vollkommen uberein. Nur nach dem mit der Imprägnation gegebenen Anstosse kommt er in eine Bewegung, welche ihn aus dem tieferen Theile des Eies zu dessen Oberfläche dem Spermakern entgegen führt.

Beide Kerne bewegen sich auf einander zu, wie es für das erste Ei der 6 . Beobachtung notirt ist, und sie waren in dem dritten Eie derselben Beobachtung schon dicht nebeneinander gelegen, ohne dass der Spermakern seine characteristische ovale Form und homogene glänzende Beschaffenheit verloren batte. Bei dem zweiten Ei der 6. Beobachtung so wie in dem ersten und zweiten Ei der 7. Beobachtung sieht man beide Kerne sich beriuhren nnd dabei, wie für zwei Eier notirt ist, in einer lebhaften amöboiden Bewegung begriffen. Diese Bewegung hat wahrscheinlich auch van Beneden gesehen, indem er seinen centralen Pronucleus als "zwei bis drei kleine Partikelchen beschreibt, die sich später zu einem grösseren centralen Körper mit ungleicher Oberfläche verbinden." 
Wahrseheinlich hatte er jedoch nicht einen klaren Fall, wie ich ihn beschrieb, mit so energischen amöboiden Bewegungen vor sich.

Bemerkenswerth ist in meinen Beobachtungen, dass die Conjugation der Kerne nicht im Centrum des Eies stattfindet, sondern in den meisten Fällen excentrisch und manchmal sogar sehr nahe an der Peripherie (drittes Ei der 6. Beobachtung).

Die strahlige Figur habe ich niemals sicher um den sich bebewegenden Spermakern gesehen; dagegen war dieselbe ohne Zweifel im Ei Figur 5 um die sich conjugirenden Kerne bemerkbar und zwar wurden die Strahlen im ganzen Dotter zerstreut gesehen, wie es auch bei niederen Thieren in diesem Falle beschrieben ist.

Weil und $\mathrm{Hensen}$ haben unzweifelhafte Spermatozoen im Innern des Dotters, theils unverändert, ja sogar beweglich, theils mit aufgeblähtem Kopfe gesehen. In der Beurtheilung dieser Fälle ist nothwendig mit Fol der Umstand in Acht zu nehmen, dass bei den Versuchen mit Sängethiereiern das Ei sehr leicht sogleich absterben kann und zwar friber als die Spermatozoen. Letztere können bei diesen Umständen in das abgestorbene Ei so leicht eindringen und auch dort im Dotter sich so bewegen, wie in jedem andern günstigen Medium. Ich selbst habe mehrere Male, bei den Versuchen mit kinstlicher Befruchtung, die zahlreichen Spermatozoen in's Ovarialei noch mit voller Corona ausgestattet, eindringen gesehen und dort sehr lebhafte Bewegungen beobachtet. Doch bin ich nicht im Stande zu beweisen, dass das Ei noch lebendig war.

Beobachtung 8. Kaninchen. Erste Begattung um 5 h. $20 \mathrm{M}$. Nachmittags; der Bauchschnitt um 9 h. 15 M. am folgenden Morgen gemacht (d. h. nach 16 Stunden) und eine Tube ausgeschnitten. Ungefähr in der Mitte der Tube wurde ein Ei (Fig. 6) gefunden, das vollkommen dem in Fig. 4 gezeichneten gleicht. Nur sieht man hier ausserdem noch ein grosses Richtungskörperchen. An dem mit Osmium behandelten Präparate, von dem die Zeichnung gemacht ist, hat letzteres eine Bisquitform.

Um $11 \mathrm{~h}$. wurde die zweite Tube ausgeschnitten und zwei Eier ungefähr in der Mitte ihrer Länge gefunden (ungefähr nach $17 \%$ Stunden). Eins von diesen ist in Fig. 7 dargestellt. Man sieht einen stark contrahirten Dotter, zwei Richtungskörperchen am Eipole in einem seichten Grübchen und einen sehr deutlichen in zwei ungleiche Theile getheilten Kern. Die beiden Theile desselben sind sehr scharf contourirt, feinkörnig, und schliessen jeder eine Anzahl von racuolenartigen Gebilden ein. Die Grenze zwischen beiden ist scharf und geradlinig.

Hinsichtlich des zweiten Eies dieser Beobachtung bin ich nicht sicher, ob es sich hier um eine Conjugation des Sperma- 
kernes mit dem Eikerne handelte, oder ob man hier schon die erste Segmentirung vor sich hat. Die scharfe Contourirung beider Kerne und ihre ähnliche Beschaffenheit spricht für die zweite Vermuthung, welcher aber die Richtung der Theilungsaxe im Vergleiche mit der Lage der Richtungskörperchen entgegensteht. Auch eine dritte Vermuthung ist nicht unmöglich, nämlich dass das ganze Gebilde nur der Eikern ist, während der Spermakern unsichtbar wäre ${ }^{1}$ ).

Auch beim Meerschweinchen habe ich dreimal Beobachtungen uber die Pronuclei gemacht und ich glaube, dass wegen des vollkommenen Mangels derartiger Beobachtungen in der Literatur alle diese drei Beobachtungen, welche die aufeinanderfolgenden Phasen des Befruchtungsprocesses darstellen, hier möglichst genau anzuftihren sind.

Beobachtung 9. Ein Meerschweinchen liess sich nach 98 Tagen der Beobachtung am 25. VI. um $6 \frac{1}{\mathrm{~g}} \mathrm{~h}$. Abends begatten. Am 26. VI. um $3^{3 / 4} \mathrm{~h}$. Morgens, d. h. $13^{1 / 4}$ Stunden nach der ersten Copulation wurde das Thier getödtet. Auf dem rechten Ovarium bemerkt man 3 frische gelbe Körper; am linken Ovarium wurden weder grosse Follikel, noch frische Corpora lutea gefunden. Alle drei ausgetretenen Eier wurden ungefähr in der Mitte der rechten Tube angetroffen. Alle zeigten noch die Reste der Corona, ferner einen contrahirten Dotter, dessen centraler Theil etwas dunkler als der peripherische aussah. Grössere und dunklere Dotterkügelchen wurden ausserdem auch im ganzen Dotter zerstreut wahrgenommen. Zwei von diesen Eiern hatten je ein grosses Richtungskörperchen, in einem. Falle von rundlicher, in dem anderen von unregelmässiger Form. Im dritten Eie mit weniger contrahirtem Dotter schien das Keimbläschen dicht der Zone anzuliegen. Es muss noch erwähnt werden, dass auf dem Dotter eines der drei Eier die Bildung eines hügelartigen Fortsatzes (s. oben) beobachtet wurde. Neben dem anderen Eie wurden 3 Spermatozoen bemerkt, welche mit ihren Köpfen die Zone berührten. Zwei Tage später wurden die mit $1^{0}$ Osmiumsäure fixirten und dann mit M üll er'schen Flüssigkeit behandelten Eier in Glycerin übertragen, und jetzt wurde bei der Untersuchung eines Eies ein höchst interessanter Befund gemacht. Das Ei (Fig. 8) hatte auch jetzt noch die im frischen Zustande beobachteten Haupteigenschaften: Rest der Corona, contrahirter Dotter und ein grosses Richtungskörperchen. Die Dotterkü̈relchen sind jedoch etwas mit Osmium überfärbt und ihre characteristische Vertheilung ist nicht mehr genau erkennbar. An einer Stelle des Dotters, unweit

1) Ein identisches Bild bei Nephelis beschreibt O. Hertwig (Morphol. Jahrb. B. III. Taf. 3 Fig. 5 als ein "Zusammentreten" des Spermakerns mit dem Eikerne. Cf. auch Pl. XXII Fig. 5 der van Beneden's und Julin's Arbeit. 
der Oberfläche, und fast parallel derselben bemerkt man eine prachtvolle "Spindel". Die Fädchen gehen aus zwei rundlichen Kernen, die an beiden Enden der Spindel gelegen sind, hervor. Der eine (untere) Kern scheint etwas grösser zu sein und ist deutlicher als der obere erkennbar, so dass die Längsaxe der Spindel etwas schief zur Ebene des Gesichtsfeldes, d. h. mit dem unteren Ende näher zum Beobachter als mit dem oberen zu liegen scheint. Die meisten Fädchen scheinen gegen die Mitte der Spindel hin unterbrochen zu sein, doch gehen einige, wie ich ganz genau beobachtet habe, direct von einer in die andere Hälfte der Spindel über. In der Nähe des Eies sind einige Spermatozoen zwischen den Zellen der Corona bemerkbar. Eines von ihnen, das mit verändertem Kopfe versehen ist, ist auf der Zeichnung dargestellt (sp).

Die folgenden Maasse so wie die Zeichnung wurden 7 Tage später, als das Ei gefunden worden war, genommen:

Grösster Durchmesser des Eies (ohne Corona)
Kleinster
Dicke der Zona

Die eben beschriebene Spindelfigur habe ich nur einmal beobachtet und wurde sie meines Wissens noch niemals am Säugethierei bis jetzt gesehen. Ueber ihre Deutung im gegebenen Falle kann ich nicht zu einem ganz sicheren Schlusse kommen. Es sind hier zwei Möglichkeiten vorhanden: entweder handelt es sich hier um die Ausstossung eines Richtungskörperchens, nämlich des zweiten (Richtungsspindel von Bütschli) oder haben wir hier •den Moment des Zusammentreffens des Spermakernes mit dem Eikern vor uns. Die erste Vermuthung scheint mir aus folgenden Grïnden weniger wahrscheinlich zu sein: 1. Die Spindel liegt an dem entgegengesetzten Pole des Eies, dem ersten Richtungskörper gegentiber, während gewöhnlich beide Richtungskörperchen nebeneinander liegen. 2. Die Axe der Spindel liegt nicht vertical, sondern fast parallel der Dotteroberfläche. Nach Fol's Beschreibung kommt dies auch bei der Ausstossung des Richtungskörperchen, aber nur im Anfange der Bildung des ersten Amphiasters, de rebut" vor. Später nimmt die Spindel eine verticale Lage zur Oberfläche an. Die excentrische Lage der Spindel spricht nicht gegen die zweite Vermuthung. Wir haben schon beim Kaninchen gesehen, dass die Conjugation der Kerne oft excentrisch stattinden kann. Dieselbe 
Erscheinung habe ich auch bei Meerschweinchen beobachtet (cf. folgende Beobachtung).

Beobachtung 10. Ein Meerschweinchen liess sich am 19. VI. um 3 h. 15 M. Nachmittags begatten und wurde am 20. VI. um 7 h. 40 M. Morgens getödtet. Ungệ̈hr $3 \mathrm{~cm}$ vom Adominalende der Tube entfernt wurde um 8 h., also ungefähr 17 Stunden nach der Copulation, ein Ei gefunden, das in Fig. 9 abgebildet ist. Keine Spur einer Corona war bemerkbar. Der Dotter stark nach der einen Seite des Eies hin contrahirt, die dunkleren und grösseren Dotterkugeln sind ungefähr in der Mitte, aber nicht genau im Centrum des Eies, unregelmässig zusammengehäuft und ausserdem im feinkörnigen Dotterprotoplasma hier und da zerstreut. Im perivitellinen Raume sah man Anfangs 3 Richtungskörperchen, von denen zwei später durch eine dünne Brücke verbunden erschienen. Während der Zeichnung war diese Brücke bedeutend dicker geworden. Beide Richtungskörperchen schienen gleich feinkörnig, mit mehreren etwas grösseren glänzenden vacuolenartigen Gebilden. Eins dieser letzteren wurde viel grösser als die anderen und hatte das Aussehen eines wirklichen Kernes. Nach einer langen und sorgfältigen Beobachtung bemerkte Professor Waldeyer zwei deutliche sich berührende Kerne im Innern des Dotters. Die Kerne waren nur hei einer besonderen Einstellung des Mikroskopes unterscheidbar, so dass die Contouren des Eies selbst dabei undeutlich sichtbar waren '). Ueber die weitere Beschaffenheit beider sich copulirenden Kerne ist nichts im Protocolle bemerkt, nur ist gesagt, dass sie von einander mittelst einer sehr scharfen geraden Linie abgegrenzt gewesen seien, und dass während weiterer Beobachtung auf dem heizbaren Objecttisch keine weiteren Veränderungen eingetreten wären. In der Tuba wurden Spermatozoen constatirt.

In der eben angeführten Beobachtung haben wir, wie mir scheint, ein weiteres Stadium derselben Erscheinung wie in Beobachtung 9. Die beiden Kerne sind näher aneinander getreten bis zur Berührung. Das geschah hier gerade an einer ebenso peripherischen Stelle des Dotters wie dort. Von Heraustreten eines Richtungskörperchens kann hier gar keine Rede sein, denn beide sind schon ansgetreten und befinden sich auf einer anderen Seite des Eies. Auch die beginnende Theilung der ersten Segmentations-

1) Diese schwere Erkennbarkeit erklärt vielleicht folgende Worte Bischoff's: „In seinem Inneren (d. h. im Inneren des Dotters im Tubareie beim Meerschweinchen) irgend einen anderen Körper, das Keimbläschen, den Kern desselben, ein neues Bläschen oder Gallertkügelchen zu entdecken gelang mir nicht." (Entwickelung des Meerschweinchen S. 18). Reichert sah dagegen einen hellen Kern im Centrum "des Tubareies bei Meerschweinchen" (l. c. S. 119). Ebenso Hensen. 
kugel ist hier unwahrscheinlich, da die Theilungsebene bei allen untersuchten Thieren meines Wissens durch das Centrum des Dotters geht. Diese Beobachtung kann daher als eine Bestätigung der Vermuthung dienen, dass in der Beobachtung 9 die Spindel wirklich beim Zusammentreten der beiden Pronuclei gebildet worden ist. Die folgende Beobachtung weist auf eine weitere Fortsetzung desselben Processes hin.

Beobachtung 11. Ein Meerschweinchen gebar am 1. Y. um $93 / 4 \mathrm{~h}$. Morgens ein einziges ausgetragenes Junge. Drei Stunden später copulirte es mehrere Male. Am 2. V. um 5 h. Nachmittags wurde es getödtet und in jeder 'Tube ungefähr in der Mitte je ein Ei rasch gefunden. - Das erste Ei wurde um $5 \frac{1}{2}$ h. untersucht und gezeichnet, d. h. ungefähr 17 Stunden nach der Copulation (Fig. 10). Der Dotter war stark nach einer Seite des Eies hin contrahirt. Das Centrum schien auf einer begrenzten Stelle viel heller als die Peripherie. Das freie Oberfläche des Dotters liess mehrere kleine Runzelungen erkennen, im perivitellinen Raume zwei Richtungskörperchen. Das grössere war sehr feinkörnig, schloss ein vacuolenartiges Körperchen ein und hatte einen amöboiden Fortsatz, der während der Beobachtung seine Form veränderte. Das kleinere Richtungskörperchen war klar (in der Zeichnung ist es viel dunkler dargestellt, als es während des Lebens war) und zeigte ebenfalls ein vocuolenartiges Gebilde. Im hellen Centrum des Eies sind zwei dicht aneinander liegende Körper deutlich bemerkbar. Einer ist rundlich, der andere nierenförmig. Der rundliche Kern ist mehr körnig und dunkler, als der nierenförmige.

Das zweite Ei hatte ebensolche Beschaffenheit und schloss auch zwei Körper in seinem Centrum ein, über deren weitere Figenschaften im Protocolle nichts angegeben ist. An dem Richtungskörperchen wurden hier ganz deutliche amöboide Bewegungen bemerkt. Mittelst dieser bewegten sich beide Körperchen auf der Oberfläche des Dotters so, dass sie nach einigen Minuten ganz aus dem Gesichtsfelde verschwunden waren.

Die eben angefïhrte Beobachtung stimmt vollkommen mit der E. van Ben ed en'schen Beschreibung der Conjugation der Pronuclei, namentlich mit dem Ende dieses Processes tiberein. Die Fig. 10 entspricht auch der einzig existirenden Zeichnung, die diesen Process am Säugethiereie zum Object hat, nämlich der Figur 7 Tafel XXII in ran Beneden's und Julin's Arbeit über die Fledermäuse. (Cf. auch meine Fig. 5).

Schliesslich habe ich hier noch 2 Eier kurz zu beschreiben, iiber deren Bedentung ich bis jetzt nicht genügend klar bin.

Eins von diesen (Figur 11) stammt von dem Kaninchen der 8. Beob- 
achtung und zwar wurde es in der zweiten Tube gefunden, also 17 Stunden nach der Copulation. An einer Stelle im Innern des contrahirten Dotters, nahe der Peripherie, sieht man ein Paar deutliche conjugirte Kerne. Am lebenden Objecte waren sie etwas grösser, lagen etwas näher zum Centrum und führten sehr lebhafte amöboide Bewegungen aus. Am entgegengetzten Pole neben den zwei ausgetretenen Richtungskörperchen war sowohl im frischen, als im fixirten Eie noch ein deutlicher grosser Körper, welcher etwas an das Keimbläschen des reifen Eies erinnerte, bemerkbar. Ich vermag nicht $z u$ entscheiden, $o b$ dies ein drittes noch nicht vollkommen ausgetretenes Richtungskörperchen oder ein zweiter Spermakern ist. Im letzteren Falle würde das $\mathrm{Ei}$ vielleicht eine abnorme Imprägnation, ähnlich den von Fol an Echinodermen beobachteten darstellen. Zwischen den conjugirten Kernen und der Peripherie des Eies war am lebenden Eie ein heller Zug, ähnlich einer Strasse zu bemerken. Dieses Gebilde, das ich bisher nur einmal beobachtete, erinnerte mich an den Spermagang der Autoren. - Ein anderes Kaninchenei (Fig. 12) hatte in der Substanz des Dotters zwei ungleich grosse rundliche Kerne, von gleicher feinkörnigen Beschaffenheit. Ausserdem schlossen beide Kerne eine Anzahl gröberer Körnchen ein. Beide Kerne näherten sich einander ein wenig während dér Beobachtung. Am wahrscheinlichsten handelte es sich auch in diesem Falle um Spermakern (der kleinere) und Eikern (der grössere), die kurz vor der Conjugation zur Beobachtung kamen. Es ist aber bemerkenswerth, dass die Eier bereits im unteren Drittel der Tube angelangt waren, so dass auch die Möglichkeit einer beginnenden Furchung nicht ganz ausgeschlossen werden kann. Seit der Copulation waren nur $151 / 2$ Stunden vertlossen.

\section{Schlussfolgerungen über Befruchtungsvorgänge.}

Nach meinen Beobachtungen glaube ich folgenden normalen Gang der Imprägnation bei meinen Versuchsthieren annehmen zu sollen.

1. Durch das erste Drittel der Tube geht das reife Ei unverändert hindurch.

2. Die Imprägnation vollzieht sich ungefähr in der Mitte der Tube.

3. Die Zellen der Corona sind dabei theilweise schon abgelöst.

4. Mehrere Spermatozoen, bei Kaninchen bis etwa 100, treten mit dem Eie zusammen; mehrere derselben dringen durch die Zona in den perivitellinen Raum hinein.

5. In die Substanz des Dotters dringt wahrscheinlich, wie bei niederen Thieren, nur ein Spermatozoon hinein.

6. Der Schwanz dieses Spermatozoons löst sich raseh auf. Der 
Kopf quilt bedeutend and bildet, vielleicht in Verbindung mit benachbarten Theilen des Dotters, den Spermakern.

7. Der Eikern ist schon friher im Ei gebildet, vielleicht meistentheils schon im Ovarium. Nach dem Erscheinen des Spermakernes nähert er sich diesem; anch der Spermakern seinerseits bewegt sich in der Richtung zum Eikern.

8. Das Zusammentreten beider Kerne geschieht gewöhnlich in einem excentrisch gelegenen Theile des Dotters.

9. Bei Meerschweinchen ist dabei eine Spindelfigur erkennbar; dieselbe kommt wahrscheinlich auch bei Kaninchen vor.

10. Die nahe aneinander getretenen Kerne führen lebhafte amöboide Bewegungen aus.

11. Dann bewegen sich die conjugirten noch nicht verschmolzenen Kerne nach dem Centrum des Eies.

12. Im Centrum des Eies dauern die amöboiden Bewegungen der conjugirten Kerne noch fort; endlich nimmt einer der Kerne eine Halbmondform an und "umarmt" den anderen Kern. Der Dotter nimmt dabei ein strahliges Aussehen an.

13. Weiter kann man nur aus der Analogie mit den anderen Thieren vermuthen, dass beide Kerne zusammenfliessen und so den „Furchungskern“ bilden.

\section{Erklärung der Abbildungen anf Tafel IX.}

Fig. 1. Kaninchen. 101/2 Stunden nach der Copulation. - Ovarialei. Umgewandelte Elemente des Discus poligerus. Einzelne in die Länge ausgezogene Zellen stehen miteinander in Verbindung mittelst langer, zum Theil verästelter Fortsätze. Das Präparat mit starker $\mathrm{NHO}_{3}$ fixirt und mit Grenacher's Carmin gefärbt. - (Hartn. Syst. VII. Oc. 3.)

Fig. 2. Kaninchen. Ovarialei. - Ein unregelmässig geformtes Keimbläschen befindet sich nahe der Peripherie des Dotters und schliesst 2 grosse Keimflecke und mehrere Nebennucleolen ein. - Dotterkern im Centrum. (Hartn. Syst. VII. 0c. 3.)

Fig. 3. Kaninchenei aus der Tube 14 Stunden nach der Begattung. Spermakern (s) und eben erschienener Eikern (e). - Zwei Richtungskörperchen, contrahirter Dotter an einem Pole. Nur wenige der beobachteten Spermatozoen sind mitgezeichnet. Der Eidotter halb schematisch ausgeführt. Frisch gezeichnet. (Hartn. Syst. VII. Oc. 3.)

Fig. 4. Kaninchen. Tubarei 14 Stunden nach der Copulation. Aus der- 
selben Tube wie Fig. 3. Conjugation der Pronuclei. - Amöboide Bewegungen derselben. Frisch gezeichnet, nur der Eidotter später und zwar halb schematisch ausgeführt. Die zahlreichen Spermatozoen sind nicht mitgezeichnet. (Hartn. Syst. VII. Oc. 3.)

Fig. 5. Kaninchen. Ei aus der ersten Hälfte der Tube, nahe der Mitte, 15 Stunden nach der Begattung. - Conjugation der Pronuclei. Amöboide Bewegungen desselben (cf. Holzschnitt VI). Radiäre Streifung des contrahirten Dotters. Zwei Richtungskörperchen und mehrere Spermatozoen im perivitellinen Raume. Gezeichnet nach einem mit Osmium und Müller'scher Flüssigkeit fixirten Präparate.

Fig. 6. Kan inchenei aus der Mitte der Tube 16 Stunden nach der ersten Begattung. Zwei Pronuclei in Conjugation begriffen. Nach dem mit Osmium behandelten Präparate. (Hartn. Syst. VII. Oc. 3.)

Fig. 7. Kaninchen aus der Mitte der Tube 17 Stunden nach der ersten Begattung.

Fig. 8. Meerschweinchen. Tubarei $13 \frac{1}{4}$ Stunden nach der Copulation. Bildung der Spindel bei der Annäherung des Spermakerns an den Eikern (?). sp Spermatozoon. - Osmiumsäure and Müller'sche Flüssigkeit. (Hartn. Syst. VIII. Oc. 3.)

Fig. 9. Meerschweinchen. Tubarei 17 Stunden nach der Begattung. Vertheilung des Protoplasmas auf eine medullare und eine corticale Schicht. - Conjugation der Pronuclei. Zwei Richtungskörp̣erchen; eins derselben vielleicht in Theilung begriffen. - Frisch gezeichnet. (Hartn. Syst. VII. Oc. 3.)

Fig. 10. Meerschweinchen. 28-29 Stunden nach der Copulation. Conjugation der Pronuclei. Zwei Richtungskörperchen mit je einer vacuolenartigen Bildung. Das grössere Richtungskörperchen hat einen amöboiden Fortsatz und scheint feinkörnig, während das kleinere klar ist. (In der Lithographie ist es zu stark körnig.) An der Oberfläche des Dotters sieht man zahlreiche kleine lappige Fortsätze. Frisch gezeichnet von Professor Waldeyer, ohne Zusatz. Protoplasma halb schematisch ausgeführt. Winckel. (Syst. VII. Oc. 3.)

Fig. 11. Kaninchen 17 Stunden nach der ersten Begattung. Ei aus der Mitte der Tube.

Fig. 12. Kaninchen $15_{1 / 2}^{1}$ Stunden nach der ersten Begattung, Ei, gefunden in dem letzten Drittel der Tube. Oben sieht man undeutlich zwei Richtungskörperchen. - Nach einem frischen Präparate gezeichnet. (Hartn. Syst. VII. Oc. 3.) 